\title{
Revisión de las especies peruanas de Sebdenia (Sebdeniales, Rhodophyta) y descripción de Cryptonemia anconensis sp. nov. (Halymeniales, Rhodophyta)
}

\author{
Revision of the Peruvian species of Sebdenia (Sebdeniales, Rhodophyta) and \\ description of Cryptonemia anconensis sp. nov. (Halymeniales, Rhodophyta)
}

Cesar Acleto 0. ${ }^{1}$ y Reina Zúñiga A. ${ }^{2}$

\begin{abstract}
1 Museo de Historia Natural, Universidad Nacional Mayor de Universidad Nacional Mayor de San Marcos, Av. Arenales 1256 , ma 14, Peru. Email: cesaracleto@yahoo.com 2 Facultad de Ciencias Biológicas, Universidad Ricardo Palma, Av. Benavides 5440 Surco, Lima 41, Perú.
\end{abstract}

Presentado: $\quad 18 / 10 / 2010$ Aceptado: 22/01/2011 Publicado online: 23/06/2011

\begin{abstract}
Resumen
Seis especies de Sebdenia Berthold 1884 han sido registradas para la flora marina del Perú: Sebdenia afuerensis, S. chinchensis, S. heteronema, S. lapathifolia, S. limensis y S. polydactyla (Howe 1914, Dawson et al. 1964, Acleto 1980). En el presente estudio reevaluamos las especies peruanas de Sebdenia, basándonos en la observación de especímenes tipos y el material existente en el herbario San Marcos (USM). Concluimos que la única especie de Sebdenia es S. flabellata registrada antes como S. polydactyla, las cinco especies restantes corresponden al género Cryptonemia las que se describen e ilustran como combinaciones nuevas y como especie nueva a Cryptonemia anconensis.
\end{abstract}

Palabras clave: Perú, Sebdeniales, Sebdenia, Halymeniales, Cryptonemia, taxonomía.

\section{Abstract}

Six species of Sebdenia have been recorded for the Peruvian marine seaweed: Sebdenia afuerensis, S. chinchensis, S. heteronema, S. lapathifolia, S. limensis and S. polydactyla (Howe 1914, Dawson et al. 1964, Acleto 1980). In the present study, we re-evaluated the Peruvian species of Sebdenia on the basis of type specimens and herbarium material of the Herbarium San Marcos (USM). We concluded that only Sebdenia flabellata previously identified as Sebdenia polydactyla is present in our marine flora. The last five species correspond to Cryptonemia genera and are described and illustrated as new combinations and Cryptonemia anconensis as new species.

Keywords: Peru, Sebdeniales, Sebdenia, Halymeniales, Cryptonemia, taxonomy.

\section{Introducción}

Las contribuciones preliminares al conocimiento de las algas marinas del Perú (Howe 1914, Taylor 1947, Dawson et al. 1964, Acleto 1973, 1980) muestran al género Sebdenia representado por las 6 especies siguientes: S. limensis (Sonder) Howe, S. lapathifolia (Kützing) Howe, S. heteronema Howe, $S$. afuerensis Taylor, S. chichensis Taylor y $S$. polydactyla (Borgesen) Balakrishnan

El registro de las especies de Sebdenia Berthold 1884 en la flora marina del Perú se inició con la descripción de Euhymenia limensis por Kützing (1849), basados en los especímenes depositados en el Binder Herbariun en Hamburgo, especímenes que según Sonder procedían del Perú por la anotación "Callao di Lima”, sin nombre del colector, ni fecha de colección. Esta especie fue posteriormente transferida a Halymenia limensis (Kützing) Sonder 1866, luego a Sarcodia limensis (Kützing) De Toni 1900 y finalmente a Sebdenia limensis (Kützing) M.A. Howe 1914, basados en los caracteres considerados por Berthold 1884 para Sebdenia.

Howe (1914), además de S. limensis (Sonder) Howe, citó a S. lapathifolia (Kützing) Howe, colectada en Paita (Hassler 121, 1872; Rijksherbaium, Leiden (L), Netherlands) y también a S. heteronema Howe, colectada en Sechura (abril-08-1907, Coker 157).

Para Perú, Taylor (1947) describió dos nuevas especies; $S$. afuerensis W.R.Taylor, colectada en las islas Lobos de Afuera por Schmitt en 1937 y S. chichensis W.R.Taylor, colectada en las islas Chincha por Schmitt en 1937.
Dawson et al. (1964) en un compendio florístico registraron para la flora marina del Perú las especies siguientes de Sebdenia: S. limensis (Sonder) Howe, S. afuerensis Taylor, S. lapathifolia (Kützing) Howe y $S$. chinchensis Taylor, incluyendo como sinónimo de $S$. limensis a $S$. heteronema Howe.

Acleto (1980) registró por primera vez para la flora marina del Perú S. polydactyla (Borgesen) Balakrishnan (considerado sinónimo de Sebdenia flabellata (J. Agardh) Parkinson por Schneider \& Wynne,1991).

Guevara (1989) realizó un estudio sobre la morfología y estructuras reproductivas de $S$. limensis (Sonder) Howe y encontró caracteres que corresponderían a las Halymeniaceae.

Lewis (1990) estudió el tipo de Euhymenia limensis Kützing 1849, basónimo de Sebdenia limensis (Sonder) Howe, y estableció una nueva combinación de Cryptonemia (Halymeniaceae): Cryptonemia limensis (Kützing) Lewis, donde incluyó como sinónimos a Sebdenia limensis (Kützing) Howe, Sebdenia chinchensis Taylor, Callymenia guaymasensis Dawson (= Cryptonemia guaymasensis (Dawson) Dawson), Cryptonemia chiangii Acleto y Cryptonemia peruviana Acleto.

En el presente trabajo, las especies peruanas de Sebdenia son revisadas en observaciones de especímenes tipos y el estudio de material existente en el herbario San Marcos (USM).

\section{Material y métodos}

Gracias a la gentileza de los curadores de los Herbarios que a continuación se indican, se han estudiado los Tipos de las especies de Sebdenia registradas para la flora marina del Perú, no así el de Sebdenia flabellata (J. Agardh) Parkinson. 
Herbario Ann Arbor, Michigan (MICH) los tipos citados por Taylor 1947: Sebdenia afuerensis Taylor y Sebdenia chichensis Taylor.

New York Botanical Garden (NY) el tipo referido por Howe 1914: Sebdenia heteronema Howe, además el tipo de Chrysymenia ? lobata Howe.

En el Herbario Leiden (L) el tipo de Sebdenia lapathifolia (Kützing) Howe e indirectamente el tipo de Sebdenia limensis (Sonder) Howe, ahora Cryptonemia limensis (Kützing) Lewis 1990, depositado en el National Herbarium of Victoria (MEL).

Se estudiaron también los ejemplares que se conservan en el Herbario San Marcos (USM) del Museo de Historia Natural de la Universidad Nacional Mayor de San Marcos.

Los caracteres vegetativos y reproductivos fueron observados en secciones transversales de 20 a $30 \mu \mathrm{m}$ de espesor logradas con el micrótomo de congelación o con una cuchilla de afeitar; teñidas con anilina azul al 1\%, acidificada con $\mathrm{HCl}$ al $1 \%$ y montadas en preparados temporales con glicerina al 50\%. Las ilustraciones que se incluyen en este trabajo corresponden a los autores.

Los dibujos se hicieron usando una cámara clara, para las fotos de los ejemplares herborizados se uso una cámara fotográfica Canon EOS 500 con lentes de aproximación, con película fotográfica de $35 \mathrm{~mm}$, las microfotográficas se tomaron con un microscopio Leitz provisto de un adaptador para la Cámara fotográfica Canon EOS 500.

\section{Resultados}

El estudio de los Tipos y ejemplares de herbario de las 6 especies de Sebdenia nos permiten reconocer en 5 de ellas $(S$. limensis (Sonder) Howe, S. lapathifolia (Kützing) Howe, S. heteronema Howe, $S$. afuerensis Taylor y $S$. chichensis Taylor) las características del género Cryptonemia (Halymeniaceae), cuyas especies tienen el talo laminar parenquimatoso, zona cortical con 2 a 3 hileras de células pequeñas fotosintéticas, zona medular con filamentos entrecruzados hialinos, algunos con contenido denso y refringente. Gametofito femenino con sistemas de ampollas de la rama carpogonial y de la célula auxiliar, cistocarpo con ostiolo no elevado, carácteres propios del género Cryptonemia según Chiang (1970).

Por el contrario S. flabellata (J. Agardh) Parkinson sería la única especie del género Sebdenia por presentar el talo cilíndrico firme a subcilíndrico, de textura elástica, corteza con 4 a 6 hileras de células pequeñas fotosintéticas y la zona medular con células ganglioideas entrecruzadas con filamentos hialinos, sin filamentos refringentes, sin sistemas de ampollas de la rama carpogonial y de la célula auxiliar, cistocarpo con ostiolo ligeramente elevado sobre la superficie del talo.

En consecuencia las cinco especies reconocidas como Cryptonemia son descritas como combinaciones nuevas y una especie nueva de Cryptonemia.

Así Sebdenia limensis (Sonder) Howe, cuyo tipo Euhymenia limensis Kützing, estudiado por Lewis (1990) es Cryptonemia limensis (Kützing) Lewis. Dawson et al. (1964) al describir S. limensis tomaron principalmente lo anotado por Howe (1914,160 - 162) y ańadieron más datos e ilustraciones correspondientes a ejemplares distintos al tipo Euhymenia limensis Kützing. Estos ejemplares estudiados más los colectados en los últimos años, así como el tipo de Chrysymenia lobata Howe corresponden a Cryptonemia, la misma que se describe en el presente trabajo como Cryptonemia anconensis Acleto et Zúńiga sp. nov.

Por otro lado, los tipos de $S$. heteronema Howe y S. lapathifolia Taylor, más los ejemplares de herbario estudiados son similares y se reúnen en una sola especie: Cryptonemia heteronema (Howe) Acleto et Zúñiga comb. nov., excluyéndose de ser sinónimo de Cryptonemia limensis (Kützing) Lewis y de S. limensis (Sonder) Howe según Dawson et al. (1964).

Sebdenia chinchensis Taylor, fue considerada por Lewis (1990) como sinónimo de Cryptonemia limensis (Kützing) Lewis. La revisión del tipo y más ejemplares de herbario nos muestra que son diferentes y en consecuencia la nominamos como Cryptonemia chinchensis (Taylor) Acleto et Zúniga comb. nov., incluyendo como sinónimo a Cryptonemia chiangii Acleto.

El tipo de Sebdenia lapathifolia (Kützing) Howe, es un ejemplar membranáceo con caracteres vegetativos y reproductivos propios de Cryptonemia (Halymeniaceae) y la denominamos Cryptonemia lapathifolia (Kützing) Acleto et Zúniga comb.nov.

\section{Taxonomía}

Phylum Rhodophyta
Clase Florideophyceae
Orden Halymeniales
Familia Halymeniaceae
Cryptonemia J.Agardh

\section{Cryptonemia anconensis Acleto et Zúñiga sp. nov.}

Sebdenia limensis (Sonder) Howe 1914: 160-162. Dawson et al. 1964: 57-58, pl. 37, fig. B, pl. 52, fig. A, pl. 53, fig. A. Ramirez 1982: 18-19, Figs. 11, 30.

Chrysymenia (?) lobata Howe 1914: 129, pl. 53, fig. 41. Dawson et al. 1964:71, pl. 66 .

$$
\text { Figs. } 1-8
$$

Thallus laminaris, membranaceus, ad tactum mollis, intense roseus vel rubescens, oblongus vel suborbicularis, usque ad $25 \mathrm{~cm}$ altus, $16 \mathrm{~cm}$ latus, disco rhyzoideo praeditus, stipite brevi, non plus quam 0,5 cm longo. Lamina in $4-8$ lobulis expansa, omnino subpalmata, lobulis oblongis lanceolatis vel digitiformibus in eodem plano dispositis, 3-10 cm longis, 1 - $4 \mathrm{~cm}$ latis in parte basali, apice gradatim acuminato, in extremo obtuso, lobuli majores ipse duplicato lobulati, margine integro aut dentato aut appendicibus marginalibus spathulatis dentiformibusve cum vel sine constrictione basi praeditis.

Structura multiaxialis, sectione transversali 60-110 $\mu \mathrm{m}$ lata in dimidio thalli; Cortex: cellulis $1-2$, exterioribus photosyntheticis, ovoideis vel angularibus, 3,5-4 $\mu \mathrm{m}$ diam. 4,5-6 $\mathrm{mm}$ longis. Subcortex: stratis $2-3$ cellularum pyriformium, fusiformiumve

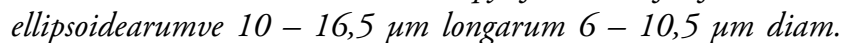
contento granulari denso, axibusque majoribus parallellis faciei; Medulla haud compacta, filis hialynis paucis, 3-4,5 $\mathrm{m}$ diam., aliquot filis contento denso refringenti. Carpogonius et cellula axillaris in distincto systemati ampullarum zonae corticalis locati. Ampulla rami carpogonici parva, omnino conica, ramis principalibus secundariisque propiis generis. Ampulla cellulae axilaris satis conspicua in zona subcorticali, utrinque laminae posita, conica, amplissima, zonam medularem expandens, filo principali cellulis $10-12$ ovoideis, filisque secundariis $4-6$, cellulis $6-8$ ovoideis; Cellula auxiliaris e basi rami secundarii oriens, ovoidea, 6-9 $4 \mathrm{~m}$ 


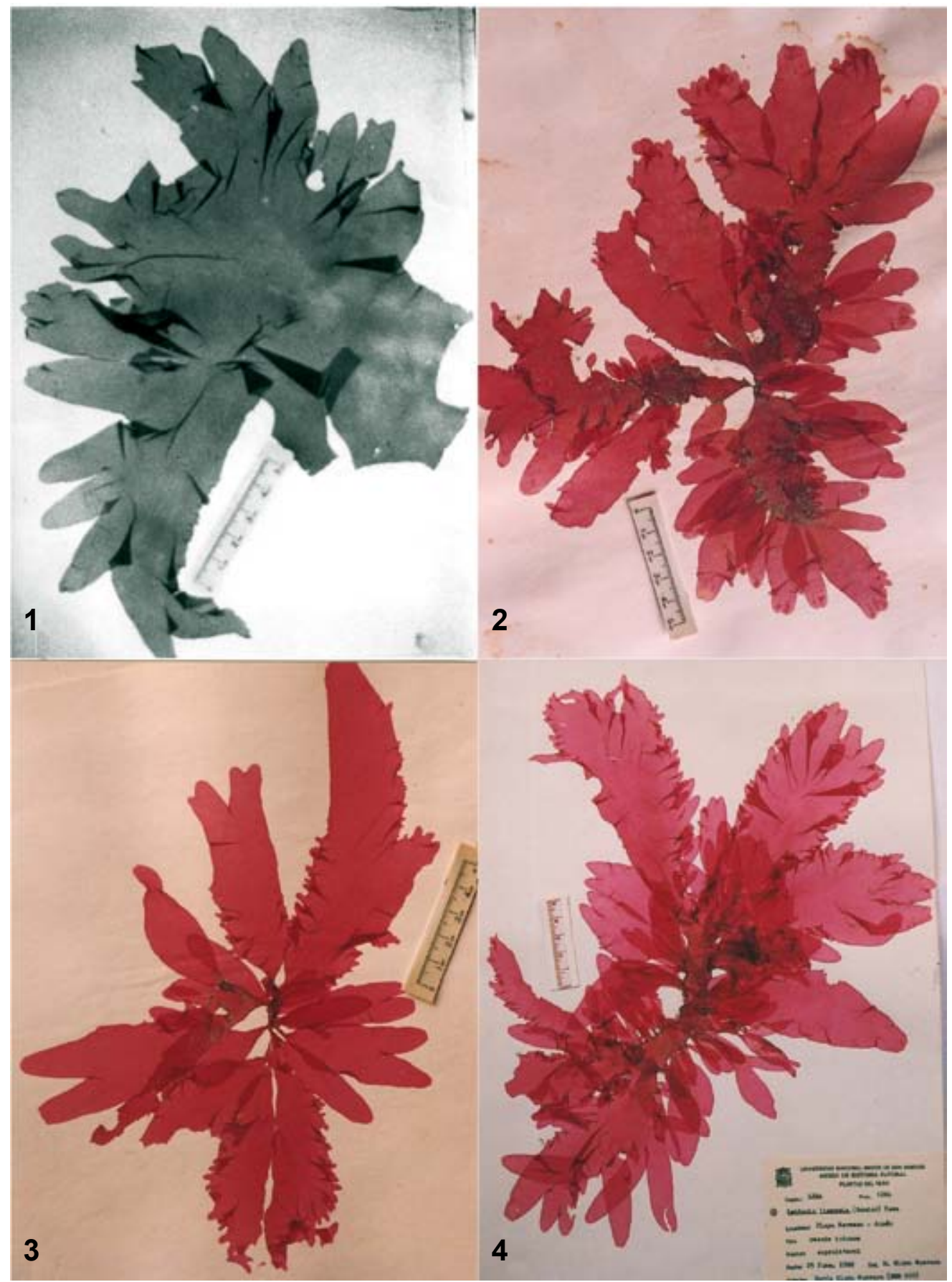

Figuras 1 - 4. Cryptonemia anconensis Acleto et Zuñiga sp. nov. (1) Tipo de Chrysymenia (?) lobata Howe 1914. (2) holotipo de Cryptonemia anconensis sp. nov. Ejemplar cistocárpico, Acleto 1188. $(3,4)$ morfología de ejemplares tetraspóricos $\mathrm{M}$. E. Guevara 0106 y 010 respectivamente.

diam., partem centralem ampullae occupat. Cystocarpus maturus ovoideus, massa carposporarum in centro, pericarpio laxo circumcinctus, ex filis medullaris contiguis constructo. Thallus in maturitate expanditur et conspicue erigitur utrinque usque ad 180 um diam., per ostiolum extrorsum aperiens. Plantas masculas non observavi.

Tetrasporophytum plantis cystocarpicis simile; Tetrasporangia in zona corticali partis mediae laminae principalis vel lobulorum secundariorum superposita, e secunda cellula corticali lateraliter orientia, ovoidea, 18 - 19,5 $\mu \mathrm{m}$ longa 5 - $9 \mu \mathrm{m}$ diam., cruciatim divisa.

Talo laminar, membranáceo, suave al tacto, rosado intenso a rojo, de contorno oblongo o suborbicular, alcanza hasta 25 $\mathrm{cm}$ de alto por $16 \mathrm{~cm}$ de ancho, con un disco rizoidal y estípite corto, no más de $0,5 \mathrm{~cm}$ de largo, se expande originando $4-8$ lóbulos, en conjunto subpalmados, lóbulos oblongo lanceolados o digitiforme en un plano, de $3-10 \mathrm{~cm}$ de largo y $1-4 \mathrm{~cm}$ de ancho en la parte basal, ápice acuminado gradualmente, obtu- so, los lóbulos mas grandes con lóbulos similares, margen liso entero o dentado, o con proliferaciones marginales espatuladas o dentiformaes con o sin constricción en su base (Figs. 1 - 4). Estructuralmente es multiaxial, en sección transversal de 60 $110 \mu \mathrm{m}$ en la parte media del talo; corteza con 1 a 2 células, la más externa fotosintética, ovoides a angulares, de 3,5-4 $\mu \mathrm{m}$ de diámetro por 4,5 - $6 \mu \mathrm{m}$ de largo, subcorteza con $2-3$ estratos de células piriforme, fusiforme o elipsoidales de $10-16,5 \mu \mathrm{m}$ de largo por $6-10,5 \mu \mathrm{m}$ de diámetro con contenido granular denso y con sus ejes mayores paralelos a la superficie; médula no compacta con pocos filamentos hialinos, de $3-4,5 \mu \mathrm{m}$ de diámetro, algunos filamentos con contenido denso, refringente. El carpogonio y la célula auxiliar se localizan en sistemas de ampollas diferentes en la zona subcortical. La ampolla de la rama carpogonial es pequeña, cónica en conjunto, con ramas principales y secundarias características. La ampolla de la célula auxiliar es muy notoria se ubica en la zona subcortical a uno 
u otro lado de la lámina, cónica de gran tamaño que expande la zona medular, con el filamento principal de $10-12$ células ovoides y $4-6$ filamentos secundarios, con $6-8$ células ovoides; la célula auxiliar se origina en la base de una rama secundaria, de forma ovoide, mide $6-9 \mu \mathrm{m}$ de diámetro y ocupa la parte central de la ampolla (Figs. 5 - 7). El cistocarpo maduro es ovoide, con la masa de carposporas en el centro, rodeado por un pericarpo no muy firme formado por los filamentos medulares contiguos, al madurar se expande y eleva notoriamente en el talo alcanzando hasta $180 \mu \mathrm{m}$ de diámetro y se abre externamente por medio de un ostiolo.
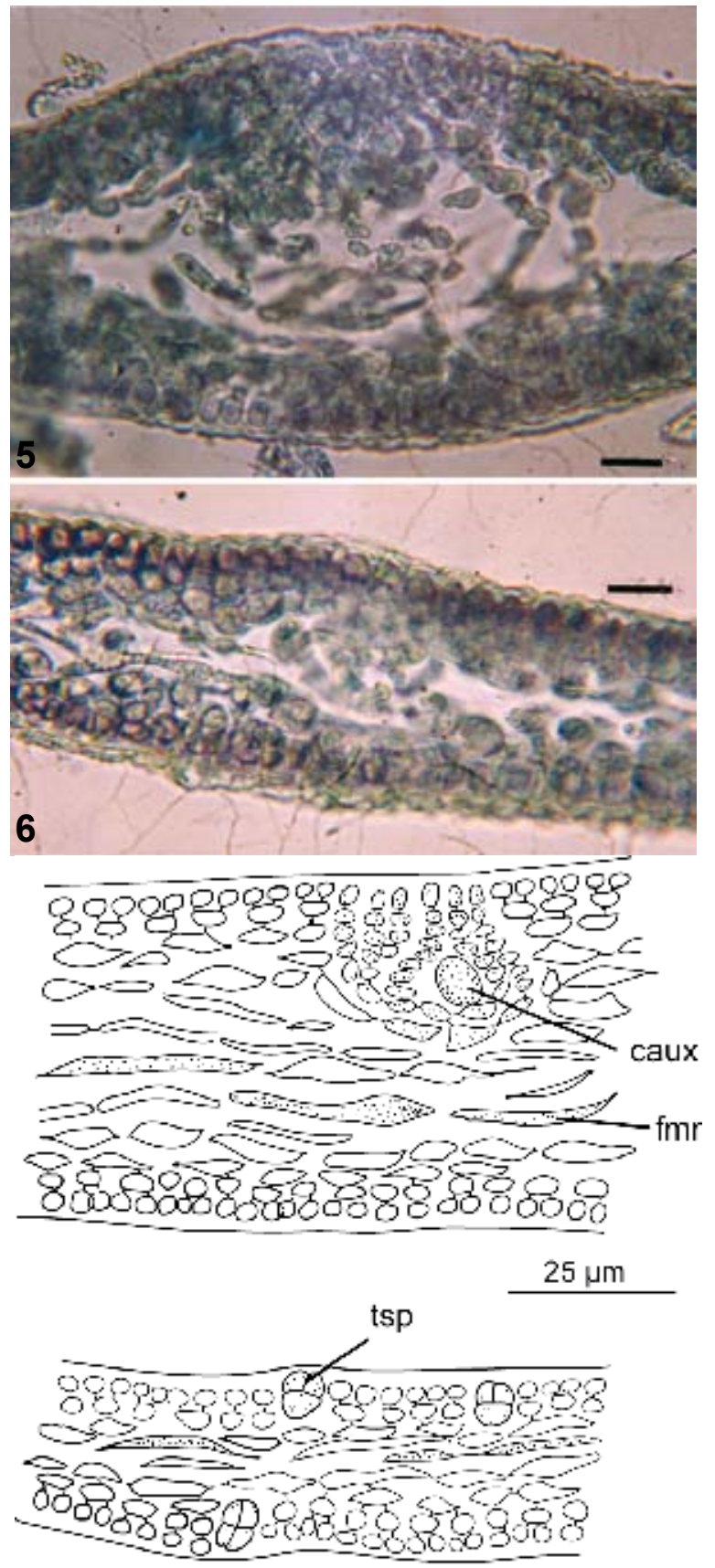

Figuras 5 - 8. Cryptonemia anconensis Acleto et Zuñiga sp. nov. (5) Sección transversal del talo cistocárpico: ampolla de la célula auxiliar, carposporas y filamentos del cistocarpo. Escala $=20 \mu \mathrm{m}$, Acleto 1188. (6) Sección transversal del talo cistocárpico: ampolla de la célula auxiliar, células fotosintéticas de la corteza, filamentos medulares hialinos y otros con contenido refringente. Escala $=20 \mu \mathrm{m}$, Acleto 1188. (7) Sección transversal del talo cistocárpico: ampolla de la célula auxiliar (caux), Acleto 1188. (8) Sección transversal del talo asexual con tetrasporangios divididos cruciadamente (ts. p.), M. E. Guevara 010 .
No se ha observado ejemplares masculinos entre los estudiados.

El tetrasporofito es morfológicamente similar a las plantas cistocárpicas. Los tetrasporangios se ubican en la zona cortical de la parte media de la lámina principal o lóbulos secundarios, se originan lateralmente de la segunda célula cortical, son ovoides y miden de $18-19,5 \mu \mathrm{m}$ de largo por $5-9 \mu \mathrm{m}$ de diámetro, tienen división cruciada (Fig. 8).

Hábitat: Esta especie habita en el sublitoral de fondo arenoso consolidado, de 5 hasta $15 \mathrm{~m}$ de profundidad, está presente durante todo el año.

Localidad tipo: Bahía de Ancón $\left(12^{\circ} 5^{\prime}\right)$, Prov. y Dpto. Lima, Perú.

Holotipo: Perú, Prov. y Dpto. Lima, bahía de Ancón, 28 octubre 1966, C. Acleto 1188 Herbario San Marcos (USM) ejemplar cistocárpico.

Etimología: El epíteto específico anconensis, está vinculado con Ancón, bahía localizada a $40 \mathrm{~km}\left(12^{\circ} 5^{\prime}\right)$ al norte de la ciudad de Lima, localidad tipo de la especie.

Material estudiado: PERÚ, Dpto. Lima, Prov. Chancay: playa El Paraíso, 19 noviembre 1960, C. Acleto 189 (USM), Prov. Lima: Pucusana, 1 octubre 1962, C. Acleto 634 (USM) (planta cistocarpica); bahía de Ancón, 30 marzo 1963, C. Acleto 665, 666 (USM); bahía de Ancón, 20 abril 1963, Dawson 24445 (USM); bahía de Ancón, 8 febrero 1964, C. Acleto 773 (USM); Prov. Callao: La Punta, 18 octubre 1964, C. Acleto 831 (USM); Prov. Lima: bahía de Ancón, 25 octubre 1964, C, Acleto 849 (USM) (planta tetraspórica); bahía de Ancón, 28 Oct. 1966, C. Acleto 1188 (USM), (planta cistocárpica, holotipo); bahía de Ancón, 18 mayo 1982, C. Acleto 2100 (USM)(planta tetraspórica); bahía de Ancón, 25 junio 1988. M. E. Guevara 005, 008, 009, 011, 030 (USM). CHILE, Antofagasta: bahía de Mejillones del Sur (ALGIOA, Franzani 449); isla Santa Maria, M. (Ramírez 426). I Región Arica: La Capilla (FUA Vilaxa 018).

Observaciones: Desde 1964 hasta el presente, numerosos ejemplares de Sebdenia limensis (Sonder) Howe similares a las ilustraciones de Dawson et al. (1964) han sido colectados entre Ancón y Pucusana, Departamento de Lima. No hubo duda acerca de la denominación de los ejemplares colectados y herborizados, sin embargo, en 1984 se observó un ejemplar (Acleto 1188, USM) correspondiente a una planta cistocárpica, con sistema de ampollas de la rama carpogonial y de la célula auxiliar propios del género Cryptonemia (Halymeniaceae) siguiendo el criterio de Chiang (1970). Este hallazgo preliminar dio origen al estudio de M.E. Guevara (1989) que incluyó los ejemplares depositados en el Herbario San Marcos (USM), su propia colección y los ejemplares citados para Chile por M.E. Ramírez (1982); sus observaciones reafirmaron que los caracteres vegetativos y reproductivos no correspondían a los de Sebdenia, sino más bien a Cryptonemia de las Halymeniaceae.

$\mathrm{Al}$ reanudar nuestros estudios sobre las especies de Sebdenia del Perú, S. limensis mereció nuestra mayor atención. Lewis (1990) dilucidó que la verdadera $S$. limensis es aquella que tiene como basónimo a Euhymenia limensis.

Santelices et al. (1989) estudiaron ejemplares de Cryptonemia colectadas en la costa norte de Chile: Antofagasta, bahia de Mejillones del Sur (SGO.095608, 095609, 0956010, 
0950011), compararon éstos con el tipo de Chrysymenia (?) lobata Howe, depositado en el New York Botanical Garden, ejemplar único, incompleto y tetraspórico colectado en la bahía de Ancón, Feb. 13, 1907, Coker 99 p., Departamento de Lima. Los caracteres integrados de esta especie y de los ejemplares chilenos dieron lugar a una nueva combinación Cryptonemia lobata (Howe) M.E.Ramírez. Santelices et al. (1989) no citan los ejemplares de Sebdenia limensis estudiados por M.E. Ramírez (1982) y no citan ningún ejemplar peruano además del holotipo. No existen hasta el presente registros de más ejemplares en nuestra flora.

El holotipo de Chrysymenia (?) lobata Howe 1914, fue también estudiado por nosotros y corresponde en sus caracteres vegetativos y reproductivos al género Cryptonemia: corteza con 2 a 3 hileras de células fotosintéticas pequeñas, médula filamentosa con algunos filamentos engrosados de contenido refringente y esporangios divididos cruciadamente. Comparado este holotipo con los numerosos ejemplares de Sebdenia limensis (Sonder) Howe, según Dawson et al. 1964, concluimos que corresponden a una especie nueva: Cryptonemia anconensis Acleto et Zúńiga sp. nov., especie endémica de la costa central del Peru, incluyéndose como sinónimo sólo al holotipo de Chrysymenia (?) lobata Howe y excluyéndose a los ejemplares chilenos estudiados como Cryptonemia lobata (Howe) Ramírez, pues aun siendo incompletos alcanzan $35 \mathrm{~cm}$ de alto y $20 \mathrm{~cm}$ de ancho, o más de $50 \mathrm{~cm}$ de alto y $30 \mathrm{~cm}$ de ancho, de $60-$ 120 um en sección transversal, talo rojo púrpura de textura firme y gruesa según Santelices (1989).

\section{Cryptonemia chinchensis (Taylor) Acleto et Zúñiga,} comb. nov.

Basónimo: Sebdenia ? chichensis Taylor 1947: 74-75, pl. 10, fig. 1. Dawson et al. 1964: 56-57, pl. 50, "chinchensis". Cryptonemia chiangii Acleto 1973: 35-38, figs. 108-112. Cryptonemia limensis (Kützing) Lewis 1990: 99-103, fig.3

Figs. $9-17$

Planta de talo laminar, rosado intenso o rojo púrpura; consiste de un rizoide parenquimatoso del cual nacen una a varias láminas primarias, espatuladas u oblongo-lanceoladas (Figs. 10, 11 y 12), provistas de un estípite corto y compreso; tienen la base cuneada, angosta, con una costa media, notoria y corta, pronto desaparece al expandirse en una lámina delgada; suave en las formas juveniles o ligeramente rígidas en las formas adultas; de margen entero, ondulado o crespado, frecuentemente erosionado, alcanzan hasta $22 \mathrm{~cm}$ de altura por $11 \mathrm{~cm}$ de ancho en su porción más amplia; las láminas primarias llevan ramificaciones marginales, espatuladas u aovadas, de base cuneada y angosta; delicadas, simples y de margen entero o grandes, divididas en 2 - 5 lóbulos marginales, con el borde ondulado o crespado; en todos los casos, con el ápice notoriamente emarginado. Estructuralmente es multiaxial; en sección transversal de 89 $110,4 \mu \mathrm{m}$ de espesor; la corteza está constituida por dos capas de células fotosintéticas, ovoides o cilíndricas, de $3-7,2 \mu \mathrm{m}$ de diámetro y $3-4$ capas de células subcorticales, ovoides, de 9 - $36 \mu \mathrm{m}$ de diámetro, las más internas son maciformes y con el protoplasto granular; la zona medular es muy angosta y está compuesta por pocos filamentos, entrecruzados, oblicuamente o periclinamente, intercalando entre ellos escasos filamentos con el contenido protoplasmático refringente.
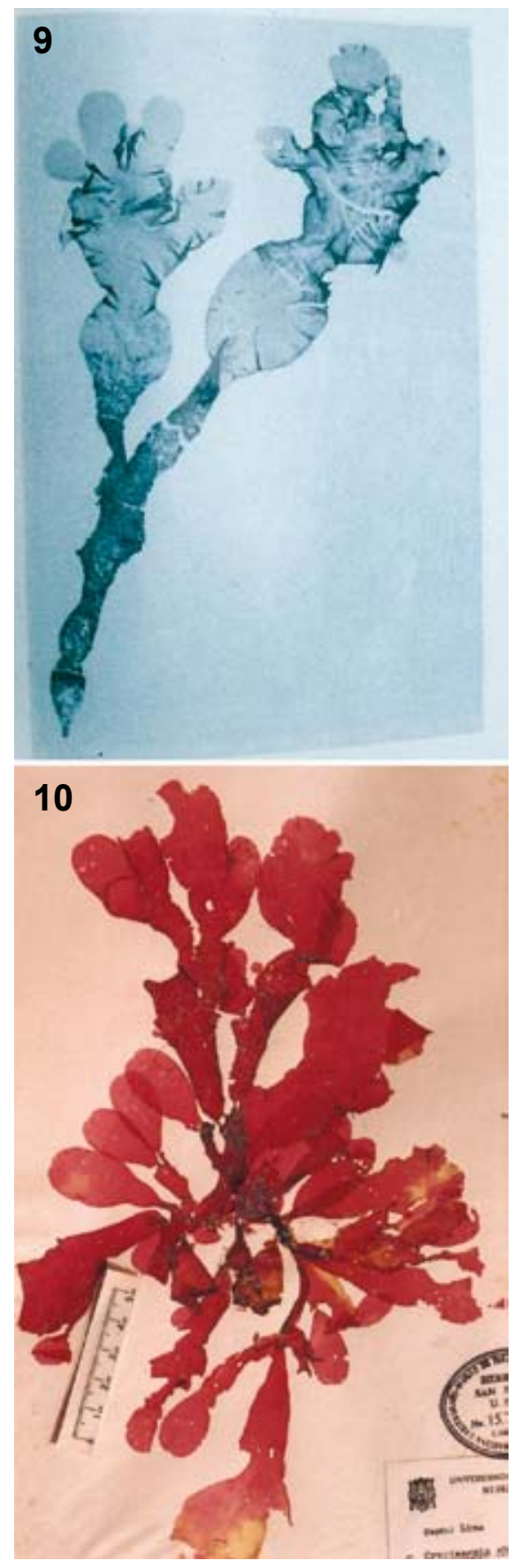

Figuras 9 - 10. Cryptonemia chinchensis (Taylor) Acleto et Zuñiga comb. nov. (9) Tipo de Sebdenia ? chichensis Taylor. (10) Holotipo de Cryptonemia chiangii Acleto, ejemplar cistocárpico, Acleto 834.

El sistema reproductivo femenino se distribuye en la zona cortical de las láminas primarias, generalmente en la zona media, en ambas superficies. La rama carpogonial y la célula auxiliar se localizan en ampollas separadas. La ampolla de la rama carpogonial (Fig. 14) es más pequeńa que la ampolla de la célula auxiliar, de forma cónica en conjunto y ramificada, las células de los filamentos primarios y secundarios son generalmente ovoides, de contenido uniforme y denso, la rama carpogonial tiene dos células, el carpogonio es cónico, con un tricogino de base ligeramente constricta, robusto y corto, no alcanza la superficie externa. La ampolla de la célula auxiliar (Figs. 13 - 16), es muy notoria por su tamaño y forma cónica, el filamento primario consta de 10 - 15 células ovoides, algunas son compresas, 


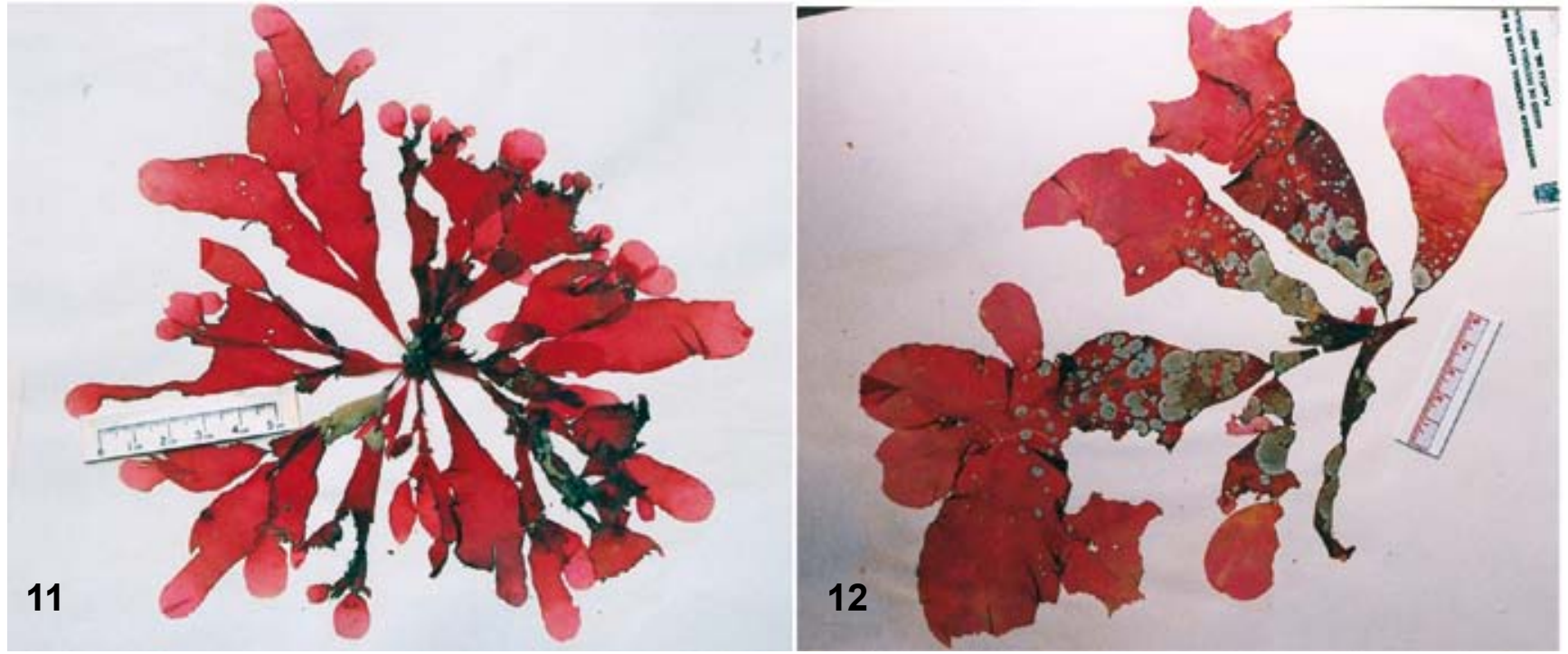

Figuras 11 - 12. Cryptonemia chinchensis (Taylor) Acleto et Zuñiga comb. nov. (11) Ejemplar tetraspórico, Acleto 1179. (12) Ejemplar tetraspórico, Acleto 2446 .
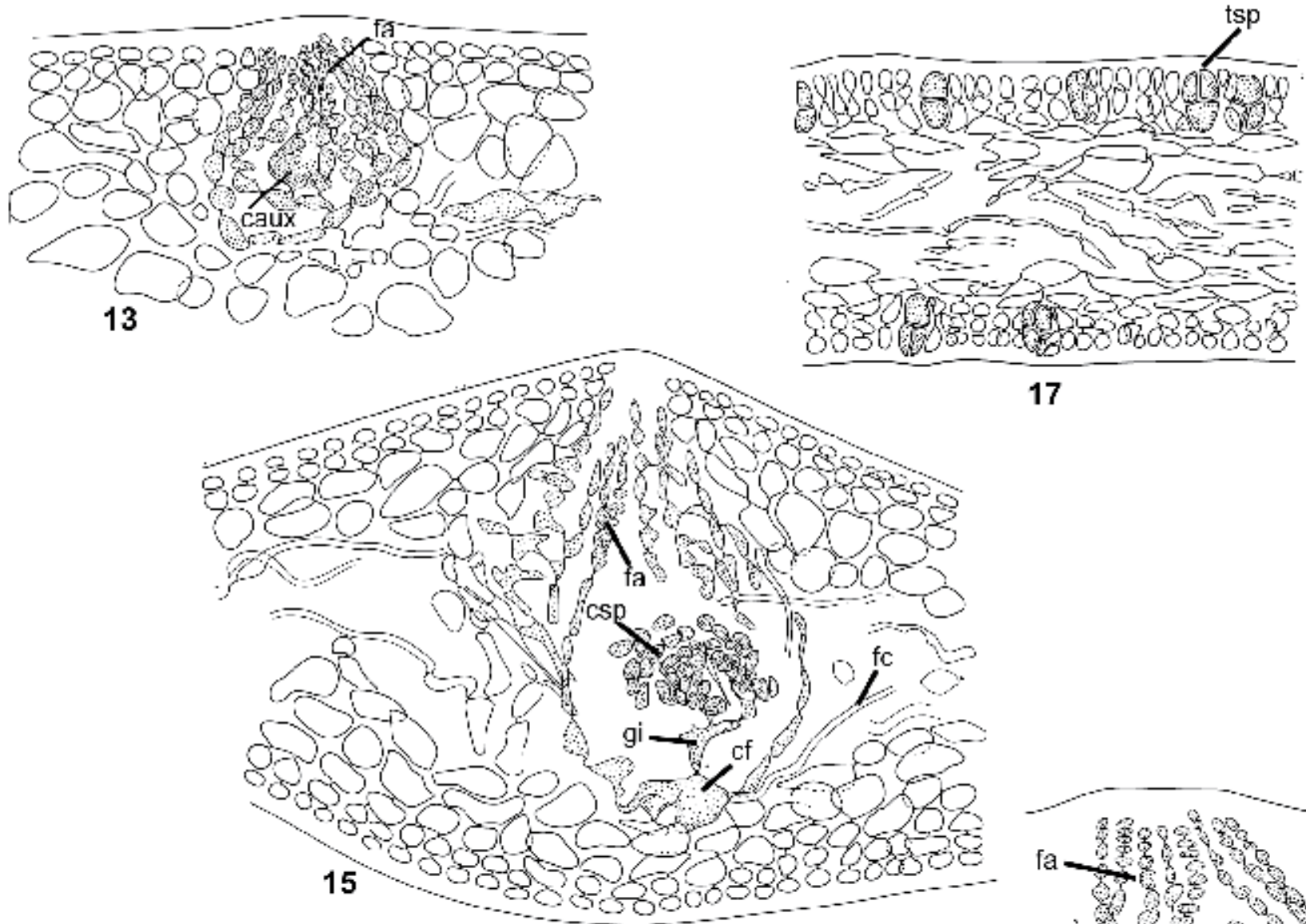

17

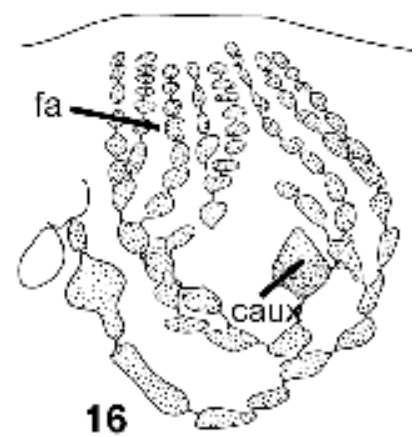

Figuras 13 - 17. Cryptonemia chinchensis (Taylor) Acleto et Zuñiga comb. nov. (13) Sección transversal del talo cistocárpico mostrando la forma y posición de la ampolla de la célula auxiliar (caux) Acleto 834 y filamentos auxiliares (fa). (14) Ampolla de la rama carpogonial, carpogonio (car). tricogino (tr) Acleto 834. (15) Formación del cistocarpo: célula de fusión (cf), filamento de conexión (fc), gonimoblasto inicial (gi) y carposporas (csp). Acleto 834. (16) Ampolla de la célula auxiliar (caux) y filamentos auxiliares (fa). Acleto 834. (17) Sección transversal del tetrasporofito, tetrasporangio con división cruciada (tsp). Acleto 1179. 
prolongadas en las uniones de las células adyacentes entre las basales, a cilíndricas en el ápice; con 4 - 5 filamentos secundarios de $7-10$ células, algunos con ramificaciones de tercer orden de $3-8$ células. Las células, terminales de los filamentos convergen en el vértice del cono y las últimas son generalmente cilíndricas, son varias veces más largas que anchas. La célula auxiliar se ubica en la base de un filamento secundario y deriva de la tercera o cuarta célula del filamento primario, en la mayoría de los casos se ha observado que es grande hasta de $29 \mu \mathrm{m}$ de diámetro, cónica, de base ancha y vértice redondeado. No se ha observado las fases iniciales en el desarrollo del gonimoblasto. Sin embargo, se ha visto, que la célula auxiliar (Fig. 15), luego de vinculada por el filamento de conexión, se alarga y aumenta de tamaño, los filamentos se separan ligeramente y descienden en la zona medular, aumentando el tamaño y la forma cónica de la ampolla original y consecuentemente origina el hinchamiento del talo en esta zona, la célula auxiliar se localiza en el fondo de la cavidad, conectada con las células vecinas de la ampolla, alargadas considerablemente y con un contenido protoplasmático homogéneo y denso. El gonimoblasto inicial, se origina de la parte media superior de la célula auxiliar, es robusto, pedicelado y orientado hacia el centro; a partir de este, se constituyen los otros por divisiones sucesivas, hasta formar una agrupación masiva, las mas externas se transforman en carposporangios. El gonimoblasto maduro ocupa el centro del cistocarpo cónico y está rodeado por un pericarpo definido de células alargadas y se comunica al exterior por medio de un ostiolo notorio.

No hemos observado las plantas masculinas de esta especie.

Las plantas tetrasporofíticas (Fig. 11) son muy similares morfológicamente a las femeninas. Esta similitud se hace ostensible en las láminas juveniles de ambas, la cuales tienen la forma ovada o espatulada, con un corto estípite, simple, de borde entero y con el ápice notoriamente emarginado. Sin embargo, difieren ligeramente por su mayor tamańo y la rigidez de su talo cuando secas. En sección transversal, la corteza tiene idéntica organización, solo la zona medular es más amplia y ocupa la mitad del espesor total y está constituida por numerosos filamentos entrecruzados oblicua o periclinalmente. Los tetrasporangios (Fig. 17), se ubican en la zona cortical media de las láminas primarias o de otros órdenes, se originan lateralmente de la segunda o tercera célula cortical; son ovoides, orientados hacia la superficie, de $19-21,6 \mu \mathrm{m}$ de longitud, por $12 \mu \mathrm{m}$ de diámetro, divididas cruciadamente.

Material estudiado: Perú, Dpto. Ica, Prov. Chincha, islas Chincha, 15 Jan. 1935, W.L. Schmitt (390-35), en Herb. Wm. Randolph Taylor, estéril (MICH). Dpto. Lima, Prov. Callao: La Punta, 18 Oct. 1964, C. Acleto (834), 15739 (cistocárpica) (USM) Holotipo de Cryptonemia chiangii Acleto (Fig. 10) Dpto. Ica, Prov. Nazca, Punta San Juan, 13 abril 1966, C. Acleto 1079 (USM) Dpto. Lima, Prov. Lima, Barranco, 23 abril 1995, C. Acleto 2446.

Observaciones: En la descripción de esta especie Taylor (1947, p. 74) existe un error tipográfico en el epíteto específico que está referido a la localidad tipo: islas Chincha, en vez de Sebdenia ? chichensis Taylor (Fig. 9), se nominó Sebdenia chinchensis Taylor tal como fue corregido por Dawson et al. 1964: 56-57. El examen del holotipo depositado en el Herbario Ann Arbor, Michigan (MICH), muestra que tiene características vegetativas propias de Cryptonemia. Taylor (1947) hizo notar la existencia de filamentos refringentes en la parte media de la zona medular.
El tipo y otros ejemplares de Cryptonemia chiangii Acleto 1973, depositados en Herbario San Marcos (USM), descritos e ilustrados con amplitud en sus caracteres vegetativos y reproductivos son similares a los de Sebdenia chinchensis Taylor, proponiéndose sea nominada por prioridad como Cryptonemia chinchensis (Taylor) Acleto et Zúñiga, comb. nov., siendo Cryptonemia chiangii Acleto, sinónimo. Cryptonemia chinchensis (Taylor) Acleto, et Zúniga comb. nov. no debe ser incluida como sinónimo de Cryptonemia limensis (Kützing) Lewis, tal como lo propone Lewis (1990: 99-104, fig. 3).

Cryptonemia limensis está representada por otros ejemplares solitarios, delicados, orbiculares en conjunto, con las ramas que se adhieren firmemente a las cartulinas del herbario mientras que los ejemplares de Cryptonemia chinchensis (Taylor) Acleto et Zúñiga comb. nov. está representada por ejemplares gregarios, firmes, espatulados en conjunto, no se adhieren totalmente a las cartulinas del herbario. Se aproxima morfológicamente a $C$. obovata de la cual se diferencia por su mayor tamaño, textura más rígida, ramificaciones abundantes y láminas amplias de ápice emarginado.

\section{Cryptonemia heteronema (Howe) Acleto et Zúñiga, comb. nov.}

Basónimo: Sebdenia heteronema Howe 1914, 163, pl. 58. Dawson et al. 1964, 57-58 como Sebdenia ? afuerensis Taylor 1947, 75, pl.10, fig. 2. Dawson et al. 1964, 55, pl. 49.

Figs. $18-25$

Talo membranoso firme, de color rojo violáceo brillante, alcanza más de $30 \mathrm{~cm}$ de altura y $25 \mathrm{~cm}$ de ancho, lámina principal de contorno oblongo, dividida subpalmadamente una a varias veces, subdicotomamente a irregular, las ramas angostadas hacia los ápices, redondeados, con proliferaciones marginales o superficiales pequeñas de 0,5 a $3 \mathrm{~cm}$ de tamaño, suborbicular, reniforme, generalmente sésiles o con pedúnculos cortos y con margen entero o irregular. Talo de $90-120 \mu \mathrm{m}$ en sección transversal en las partes superior y media respectivamente, diferenciada en una corteza de 3 hileras de células pequeñas, fotosintéticas, de $4-8 \mu \mathrm{m}$ de diámetro y $4-16 \mu \mathrm{m}$ de longitud, con pared celular definida; zona medular compuesta por muchos filamentos delgados, de $5-7 \mu \mathrm{m}$ de diámetro, contenido homogéneo, entrecruzados apretadamente, ramificados y originados de las células subcorticales, algunos filamentos de la parte media con extremos engrosados, contenido homogéneo y refringente (Figs. 21, 22). Tetrasporangios en ambas cortezas se originan lateralmente de la base de la tercera célula subcortical, mide $15-21 \mu \mathrm{m}$ de largo por $9 \mu \mathrm{m}$ de diámetro, con división cruciada (Figs. 23 y 24).

No se han observado ejemplares cistocárpicos, ni masculinos.

Material estudiado: Tipo de Sebdenia heteronema Howe, 1914 (Fig. 19), dragado a 5 pies de profundidad en la bahía de Sechura, Prov. Sechura, Dpto. de Piura, abril 8, 1907, Coker 157 p. espécimen tetraspórico depositado en el herbario del New York Botanical Garden (NY); Matacaballo, Sechura, Provincia de Sechura, Dpto. de Piura, Acleto 1994, (USM), ejemplar tetraspórico. Tipo de Sebdenia ? afuerensis Taylor 1947 dragado a 35 - $40 \mathrm{~m}$ en la Bahía Norte de las islas Lobos de afuera, Provincia de Sechura, Dpto. de Piura, enero 17, 1935, Schmitt 392A, espécimen depositado en Herbario Ann Arbor, Michigan (MICH) (Fig. 18). 


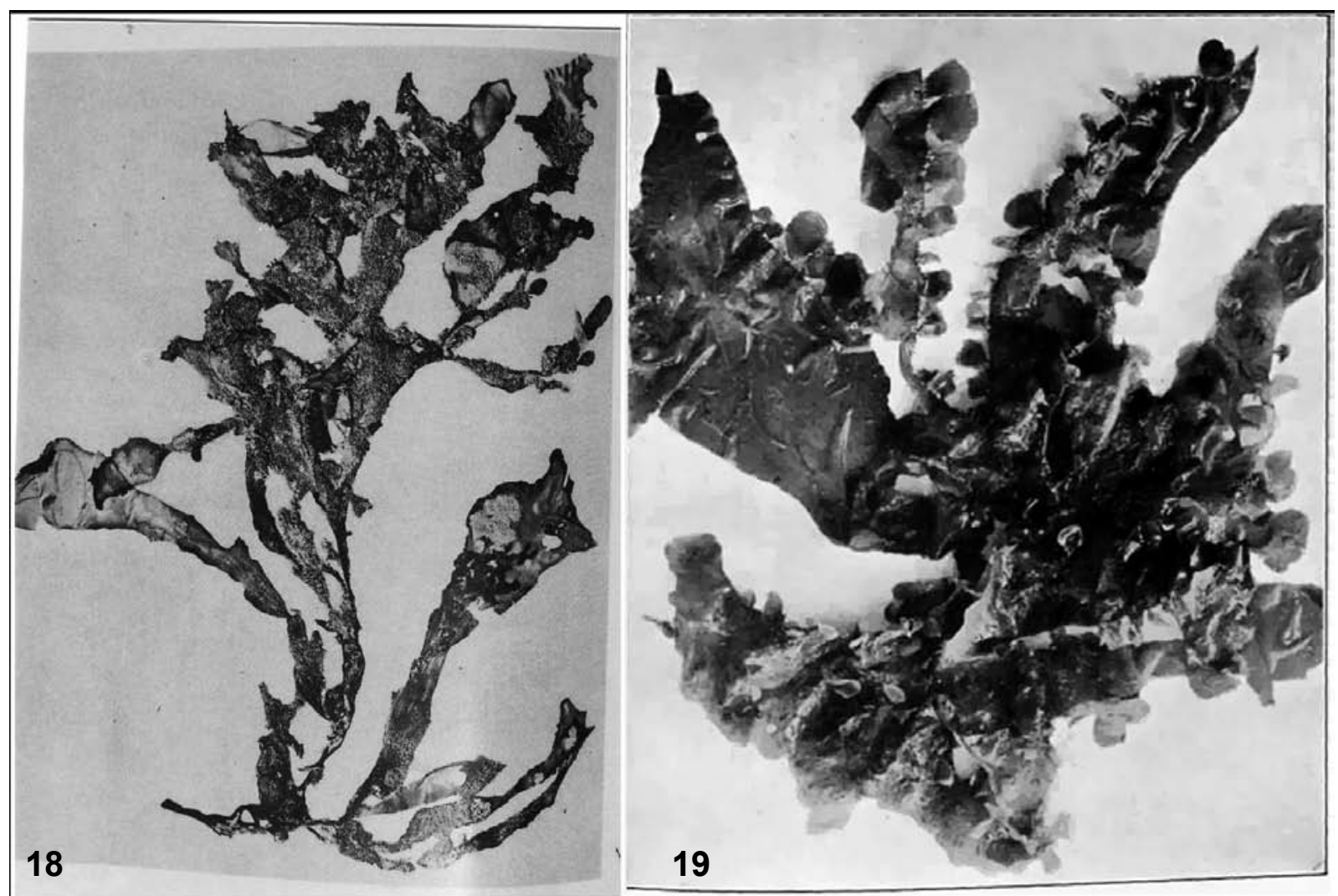

Figuras 18 - 19. Cryptonemia heteronema (Howe) Acleto et Zuñiga, comb. nov. (18) Tipo de Sebdenia ? afuerensis Taylor. (19) Tipo de Sebdenia heteronema Howe.

Observaciones: En la descripción que hace Howe (1914, p. 164) acerca de los filamentos refringentes presentes en la zona medular de Sebdenia heteronema afirma que estos son generalmente rectos, algunas veces curvados, irregularmente hinchados y pueden ser observados con nitidez a través de la corteza en observación externa, su presencia -agrega- debe ser tomado en cuenta como un carácter que justifique una segregación genérica y por extensión los caracteres vegetativos afines de las especies de Sebdenia deben ser más estudiados, de igual modo lo relacionado con el desarrollo del cistocarpo.

Las observaciones de Howe (1914), la reafirmamos al estudiar el Tipo de Sebdenia heteronema y el único ejemplar adicional

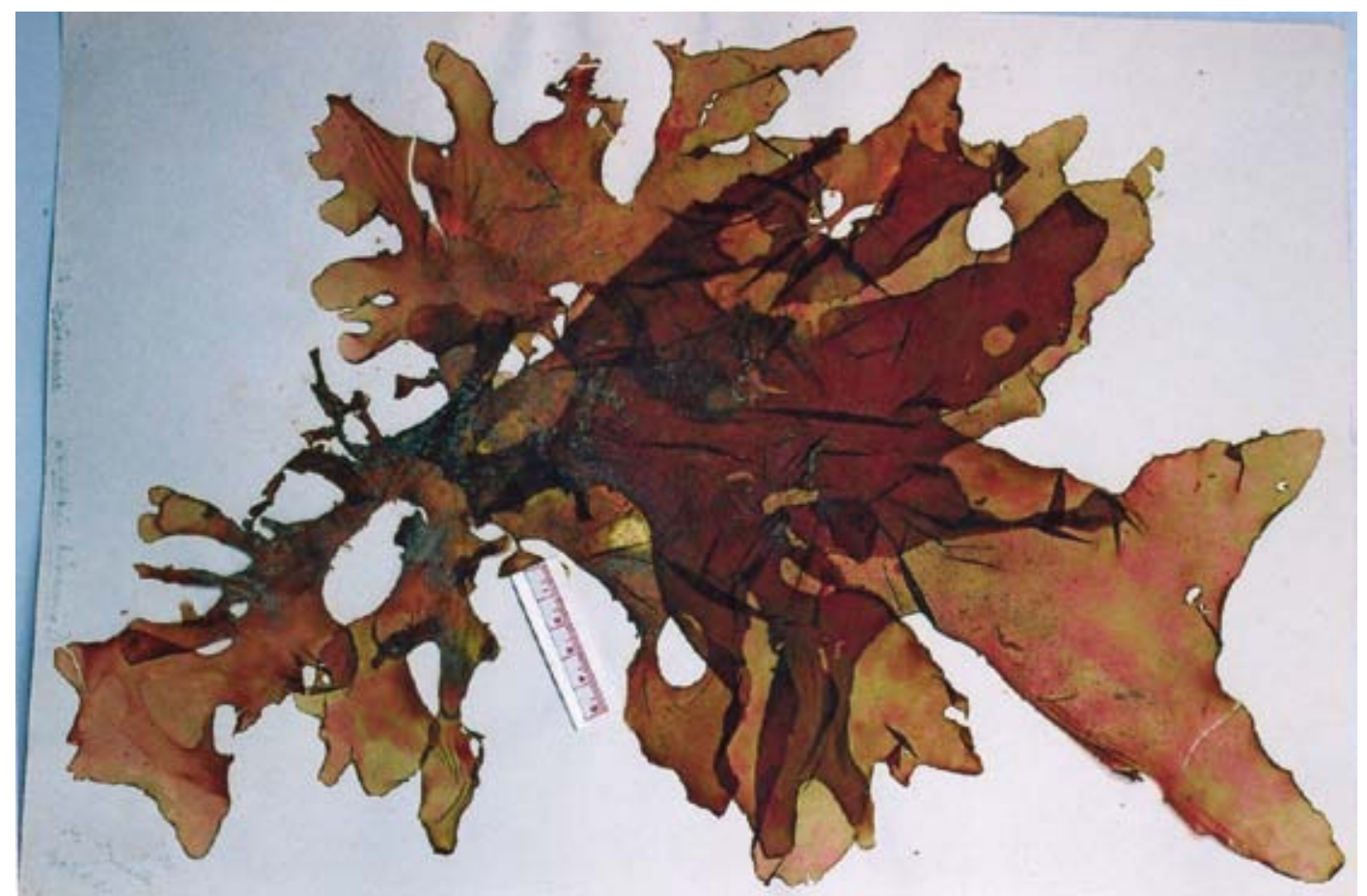

Figuras 20. Cryptonemia heteronema (Howe) Acleto et Zuñiga, comb. nov. ejemplar tetraspórico Acleto 1994. 

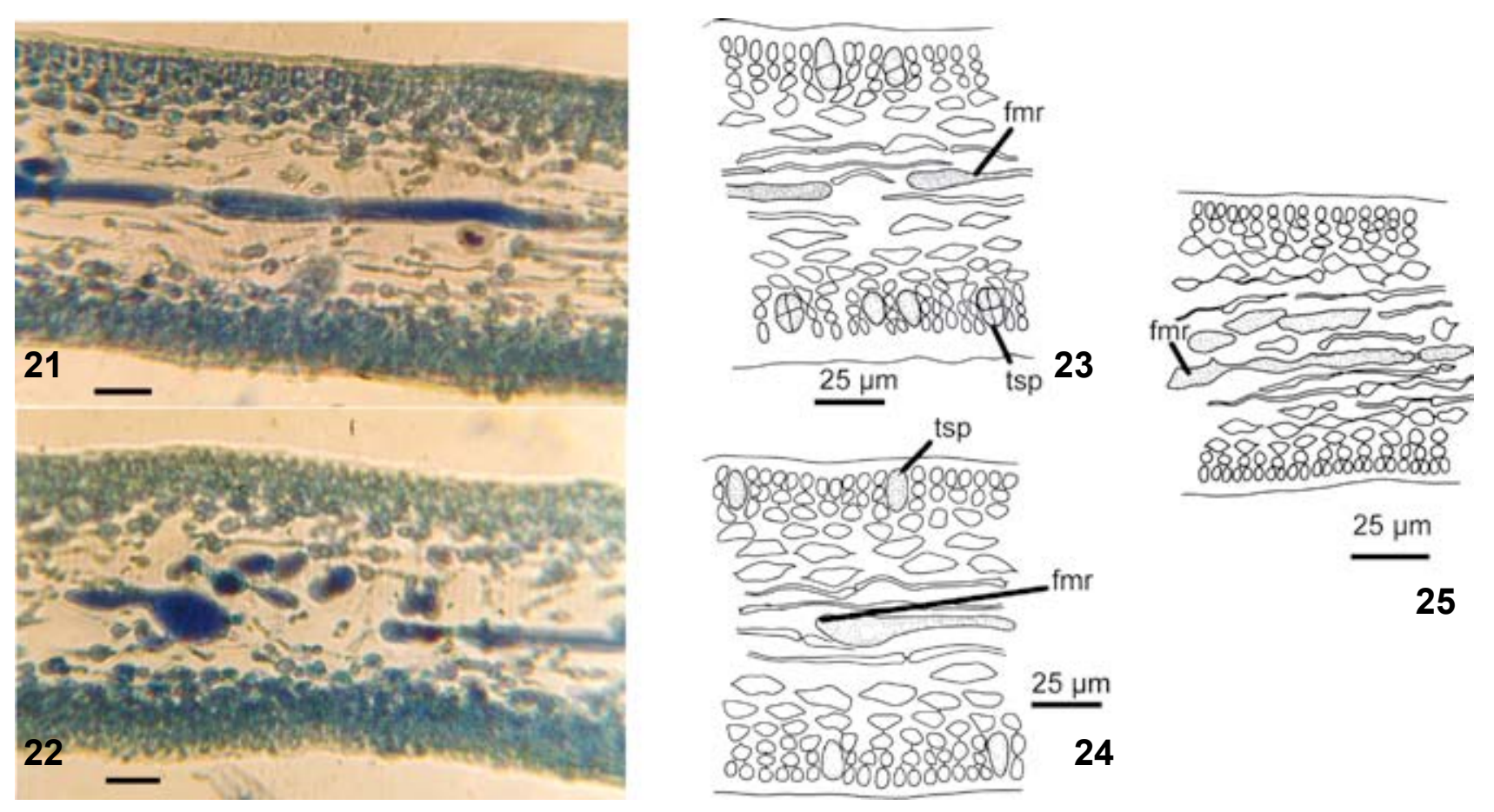

Figuras 21 - 25. Cryptonemia heteronema (Howe) Acleto et Zuñiga, comb. nov. (21) Sección transversal del talo de Cryptonemia heteronema (Howe) Acleto et Zuñiga con filamentos medulares de contenido denso y refringente. Escala $=20 \mu \mathrm{m}$, Acleto 1994. (22) Sección transversal del talo del tipo de Sebdenia ? afuerensis Taylor, con filamentos medulares de contenido denso y refringente propio de Cryptonemia, Escala $=$ $20 \mu \mathrm{m}$. (23) Sección transversal del talo del tipo de Sebdenia heteronema Howe, tetrasporangios corticales con división cruciada y filamentos medulares con contenido denso y refringente (fmr). (24) Sección transversal de Cryptonemia heteronema (Howe) Acleto et Zuñiga, tetrasporangios en la zona cortical, algunos filamentos medulares de contenido denso y refringente (fmr), Acleto 1994. (25) Sección transversal del talo del tipo de Sebdenia ? afuerensis Taylor, algunos filamentos medulares con contenido denso y refringente (fmr).

conservado en el Herbario San Marcos (USM, Acleto 1994) y por extensión a lo observado en las otras especies peruana de Sebdenia, excepto S. flabellata (J. Agardh) Parkinson.

Dawson et al. (1964, p. 58) consideraron que Sebdenia heteronema debe ser sinónimo de Sebdenia limensis (Kützing) Howe (=Cryptonemia limensis (Kützing) Lewis), puesto que algunos de los ejemplares estudiados tienen expansiones y prolongaciones marginales y superficiales similares al Tipo de Sebdenia heteronema (Fig. 19), y expresan también que es difícil distinguir de Sebdenia limensis de otras especies como Sebdenia afuerensis y Sebdenia? chinchensis.

Lewis (1990) al estudiar Euhymenia limensis Kützing, basónimo de Sebdenia limensis (Kützing) Howe, reconoció que corresponde a una combinación nueva: Cryptonemia limensis (Kützing) Lewis. Luego de estudiar el Tipo de Sebdenia ? afuerensis opina que parece corresponder al Tipo de Sebdenia heteronema, ambas en sección transversal de la parte vegetativa tiene características de las Halymeniaceae. En este estudio reafirmamos estas características vegetativas propias de Cryptonemia (Halymeniaceae) y reconocemos como combinación nueva a Cryptonemia heteronema (Howe) Acleto et Zúńiga, comb. nov. y como sinónimo Sebdenia ? afuerensis Taylor (Figs. 18 -25).

El único ejemplar de Cryptonemia heteronema existente en el Herbario San Marcos, corresponde al colectado en la playa Matacaballo, Sechura, Acleto 1994 (USM) (Fig. 20). Este ejemplar es laminar, con una base cuneada, angosta de $3 \mathrm{~mm}$ de ancho hacia el disco basal, mide de $32 \mathrm{~cm}$ de largo por $25 \mathrm{~cm}$ en la parte más ancha, con el extremo distal ramificado, con 5 lóbulos laminares laterales, cada una tiene la misma forma que la lamina principal, en conjunto es de forma palmada. Cada lóbulo primario, tiene a su vez lóbulos secundarios de forma similar, bifurcado a trifurcado, con el ápice agudo o ampliamente redondeado; el borde generalmente ondulado o con denticiones finas e irregulares, con ramificaciones lingüiformes a espatuladas en los márgenes cercanos a la base. En sección transversal el talo laminar a nivel del tercio medio mide de $66-110 \mu \mathrm{m}$; corteza con 4 hileras de células, médula filamentosa, con filamentos delgados de $5-7 \mu \mathrm{m}$ de diámetro, suavemente entrecruzados, algunos filamentos refringentes largos, de igual diámetro o ensanchados en sus extremos. Este ejemplar único tiene tetrasporangios en ambas cortezas, miden de $10-20 \mu \mathrm{m}$ de diámetro por 7,5 $\mu \mathrm{m}$ de largo, se originan lateralmente de la tercera célula subcortical.

\section{Cryptonemia lapathifolia (Kützing) Acleto et Zúñiga, comb. nov.}

Basónimo: Halymenia lapathifolia Kützing 1866, Tab. Phyc. Vol.16, pl.99. Sebdenia lapathifolia (Kützing) Howe 1914, P. 162. Taylor 1947, p. 57 , pl. 51.

$$
\text { Figs. } 26-30
$$

Talo membranáceo, lanceolado-elongado de $35 \mathrm{~cm}$ de largo y $6 \mathrm{~cm}$ de ancho, márgenes subentero, ligeramente ondulado con lóbulos cortos o dientes esparcidamente de la base al ápice; en sección transversal de $110-205 \mu \mathrm{m}$; corteza con 2 a 5 hileras de células fotosintéticas, dispuestas en hileras anticlinales, las más externas de $4-8 \mu \mathrm{m}$ de diámetro por $8-15 \mu \mathrm{m}$ de longitud, poligonales en vista superficial y con la pared celular definida, consistente; zona medular con filamentos delgados hialinos, de 3-7 $\mu \mathrm{m}$ de diámetro, sueltos a compactos, con pocos filamentos de contenido refringente. Cistocarpos inmensos entre la zona subcortical y la médula ligeramente elevada hacia la superficie 

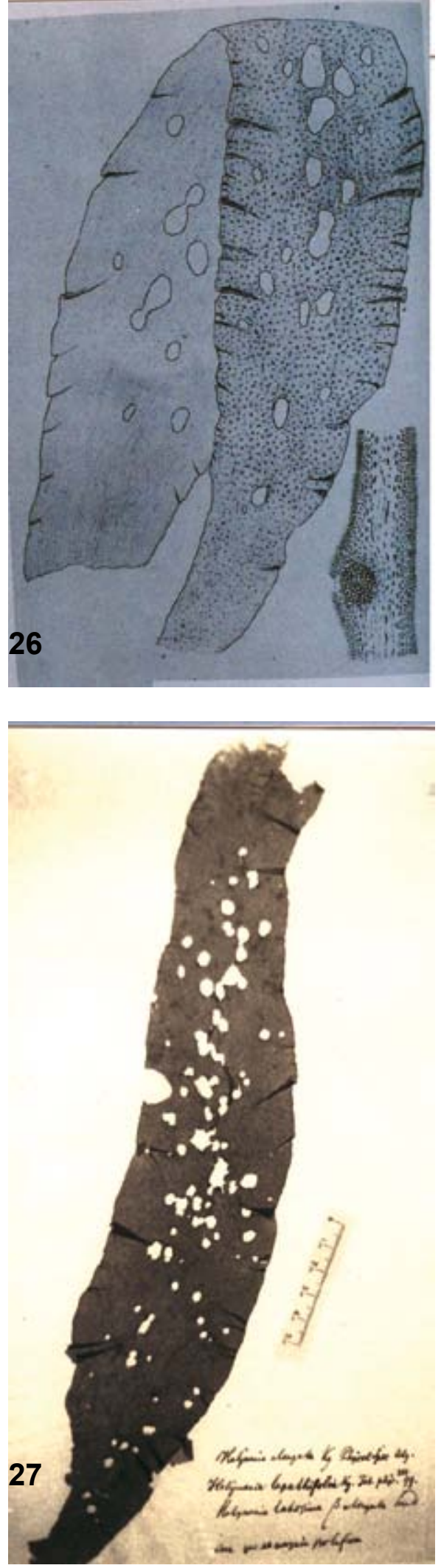

externa, carposporas formando una masa globosa de 55-85 $\mu \mathrm{m}$ de diámetro incluidas en un pericarpo definido (Figs. 28, 29).

Material estudiado: Perú, Dpto. Piura, Prov. Paita, Paita, Hassler 121, ejemplar (cistocarpico) depositado en la colección del Rijkherbarium, Leiden (L), Netherlands (Fig. 27). Desde aquella época hasta el presente no se ha registrado otros ejemplares de esta especie en nuestra costa.
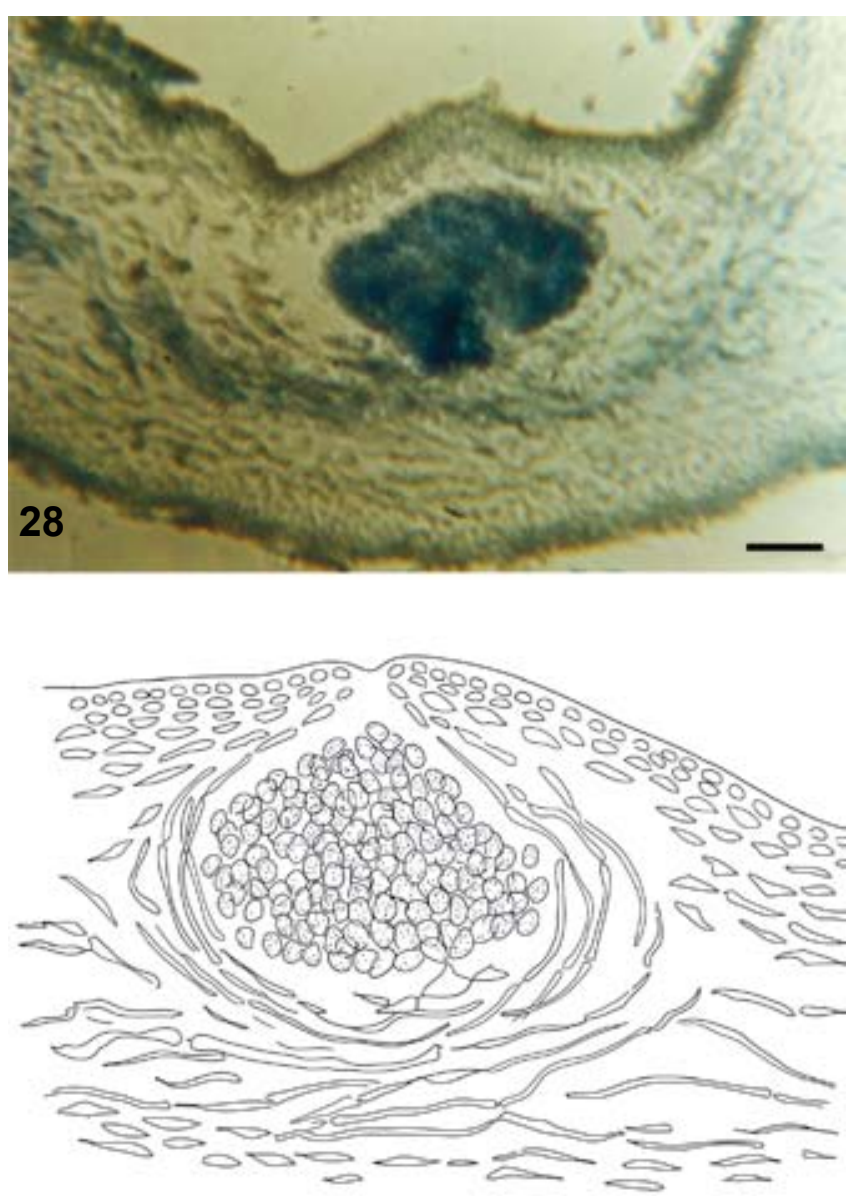

29

$25 \mu \mathrm{m}$

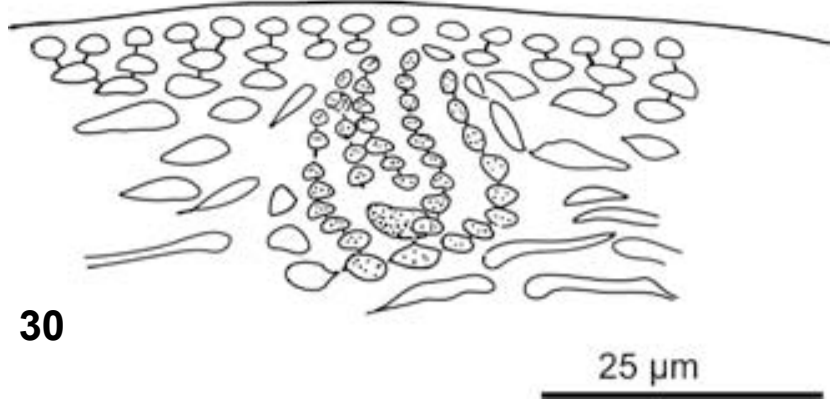

Figuras 26 - 30. Cryptonemia lapathifolia (Kützing) Acleto et Zuñiga, comb. nov. (26) Halymenia lapathifolia Kützing. Tab. Phyc. Vol. 16, pl. 99. (27) Ejemplar tipo de Halymenia lapathifolia Kützing. (28) Sección transversal del talo cistocárpico del tipo de Halymenia lapathifolia Kützing. Escala $=20 \mu \mathrm{m}$. $(29,30)$ Sección transversal del tipo de Halymenia lapathifolia Kützing, con una masa de carposporas rodeadas por los filamentos del pericarpo y ampolla de la célula auxiliar respectivamente.

Observaciones: El ejemplar estudiado tiene las características vegetativas y reproductivas propias de Cryptonemia. La médula es filamentosa, con algunos filamentos medulares refringentes. Las ampollas de la rama carpogonial y de la célula auxiliar similares a los de Cryptonemia, los cistocarpos globosos inmersos en el talo (Figs. 28 - 30). 


\section{Cryptonemia limensis (Kützing) Lewis}

Basónimo: Euhymenia limensis Kützing, Sp. Alg. 743, 1849; J. Agardh 1851: 289 Cryptonemia limensis (Kützing) Lewis 1990: 98 - 104, figs. 1 - 8. Halymenia limensis Sonder ex Kützing 1866, 34, pl. 97. J. Agardh 1876: 141. Sarcodia limensis (Kützing) De Toni 1900:416. Sebdenia limensis (Sonder) Howe 1914:160-162 Dawson et al. 1964: 57 - 58, pl.37, fig. B, pl. 52, fig. A, pl. 53, fig. A. Silva, P. C., E. G. Meñez and R. L. Moe 1987:40 Sebdenia (?) chichensis Taylor 1947:74.75, pl. x fig. 1; Dawson et al. 1964: 56 - 57, pl. 50. "chichensis". Cryptonemia guaymasensis (Dawson) Dawson 1954: 263 - 264 Cryptonemia chiangii Acleto 1973: 35 - 38, figs. 108 -112. Cryptonemia peruviana Acleto 1973:38-40, figs. 115 - 122.

$$
\text { Figs. } 31-40
$$

Talo laminar, en conjunto de contorno orbicular (Figs. 32 - 34), alcanza hasta $25 \mathrm{~cm}$ de altura, rosado o rojo púrpura, la lámina principal es corta, de base cuneada, de $2 \mathrm{~cm}$ de ancho, de margen entero y ondulado se divide en su extremo distal y lateral en 4 o 5 lóbulos, estos son palmado-cuneados, de base angosta de $1-2,5 \mathrm{~cm}$ y luego se expande hasta alcanzar de $4-8$ cm en su parte más ancha, nuevamente lobulada en su extremo distal, flexuoso, de ápice redondeado, amplio, de borde entero y crenulado. Estructuralmente es multiaxial. En sección transversal (Fig. 35) de $60-84 \mu \mathrm{m}$ de ancho, la corteza está compuesta de 3 - 4 capas de células las cuales decrecen en tamaño hacia la superficie del talo, las 2 más externas son ovoides, cilíndricas, fotosintéticas las más internas ovoides o alargadas maciformes, con abundante contenido granular, la médula comprende $1 / 3$ del espesor del talo y está compuesta de filamentos ramificados, de células alargadas unidas por sus extremos, generalmente orientado periclinalmente; algunas células del filamento medular contiene material refractivo denso.

La rama carpogonial y la célula auxiliar se localizan en ampollas diferentes; éstas se distribuyen en la zona cortical de la lámina principal y las láminas secundarias. La ampolla de la rama carpogonial (Fig. 36) es más pequeña que la de la célula auxiliar; consta de un filamento principal de 8 células, 3 - 4 filamentos secundarios. Las células de la ampolla son ovoides o globosas, la rama carpogonial consta de 2 células, el carpogonio es cónico,

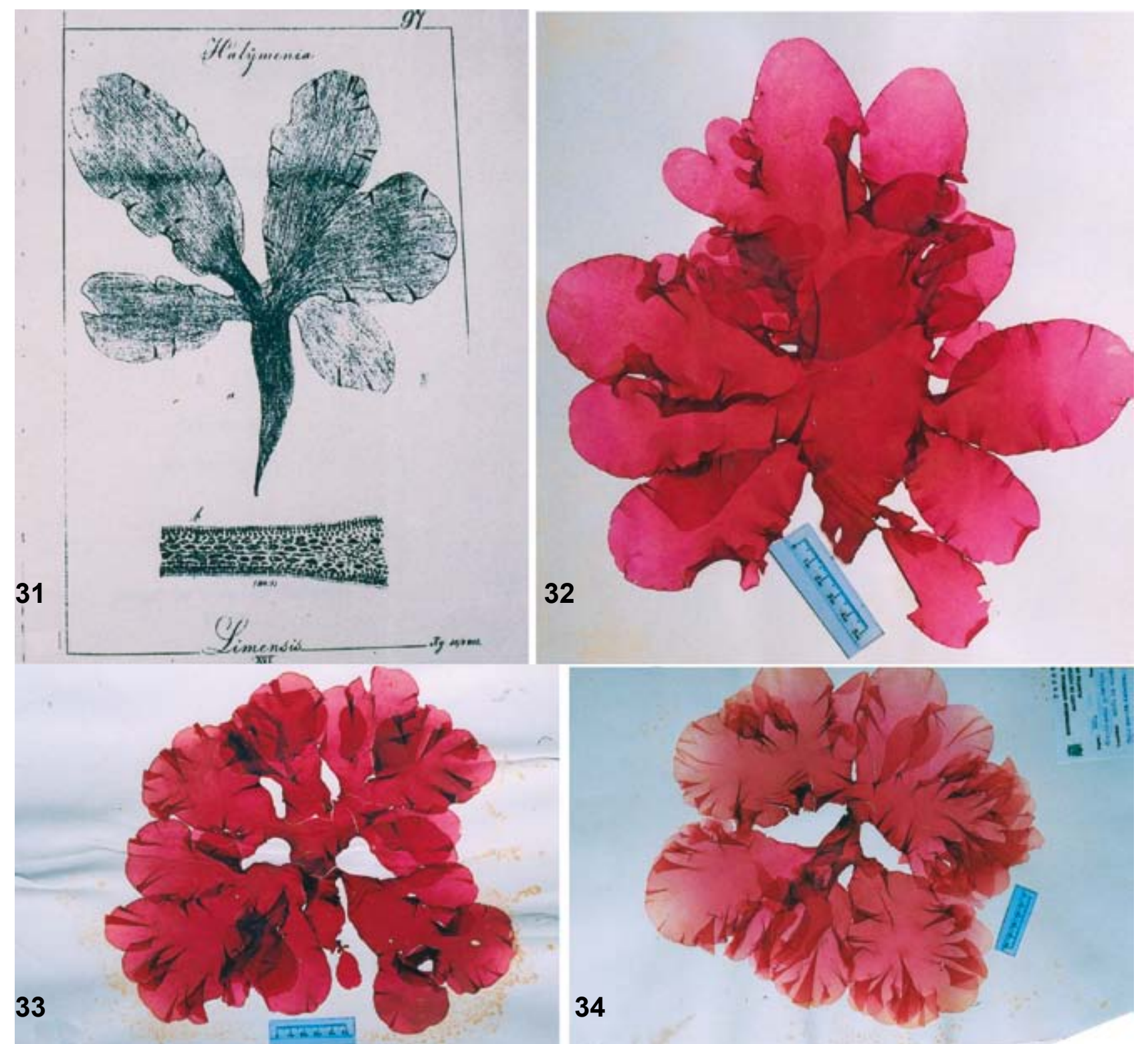

Figuras 31 - 34. Cryptonemia limensis (Kützing) Lewis. (31) llustracion del lectotipo de Euhymenia limensis Kützing (Tabulae phycologicae, vol. XVI, pl. 97). (32) Ejemplar tetrasporica de Cryptonemia limensis (Kützing) Lewis, S. Chavez s. n. (33) Holotipo de Cryptonemia peruviana Acleto, Acleto 1339. (34) Ejemplar tetraspórico de Cryptonemia peruviana Acleto, Acleto 1339a. 


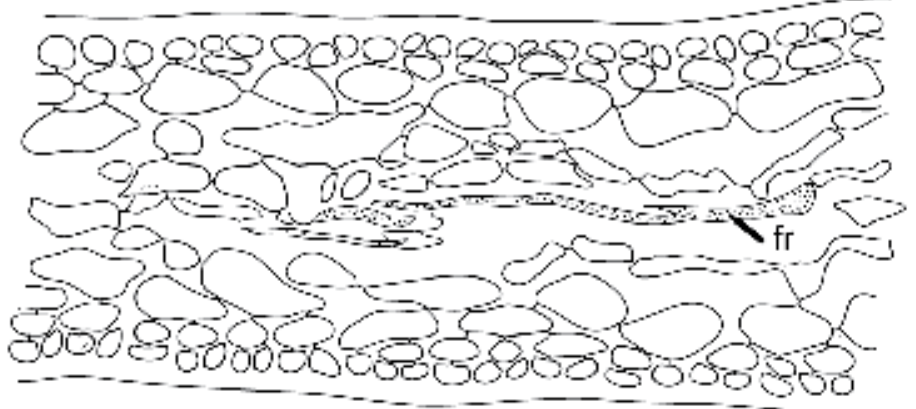

35

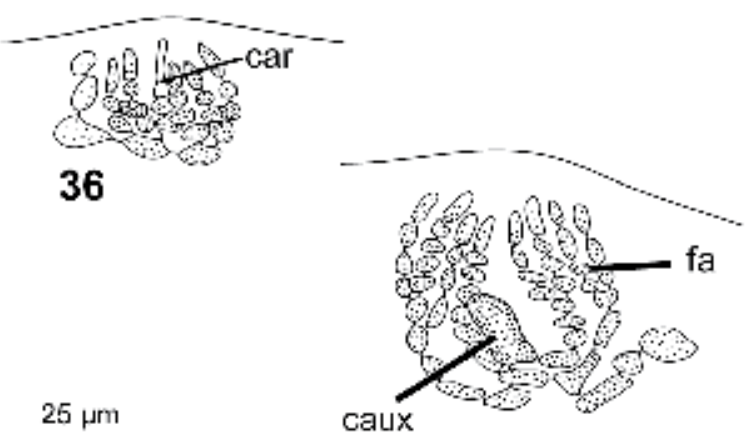

37
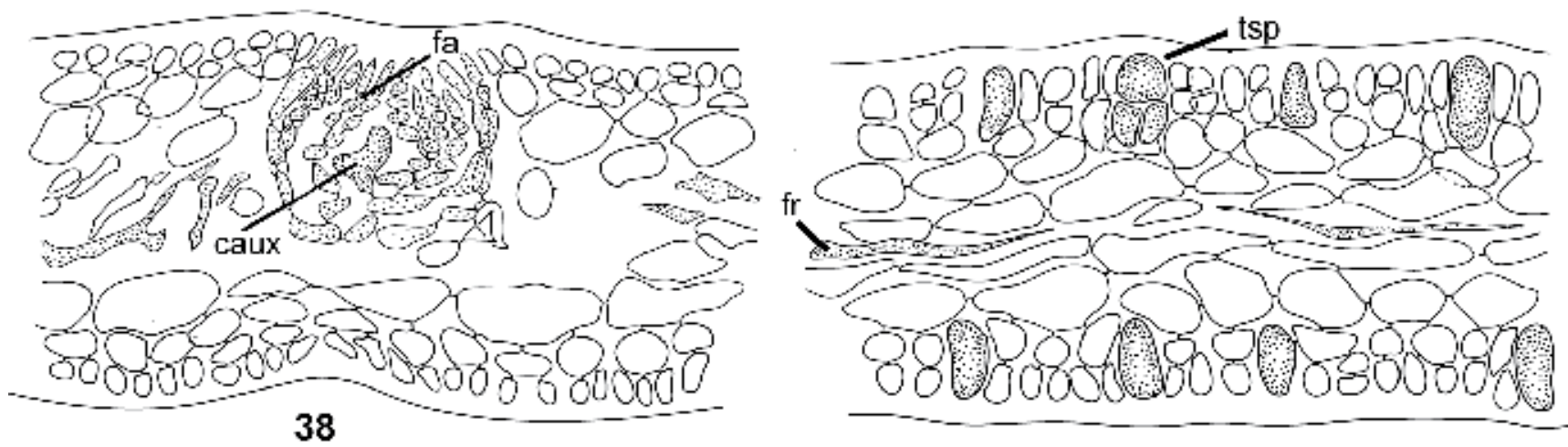

40

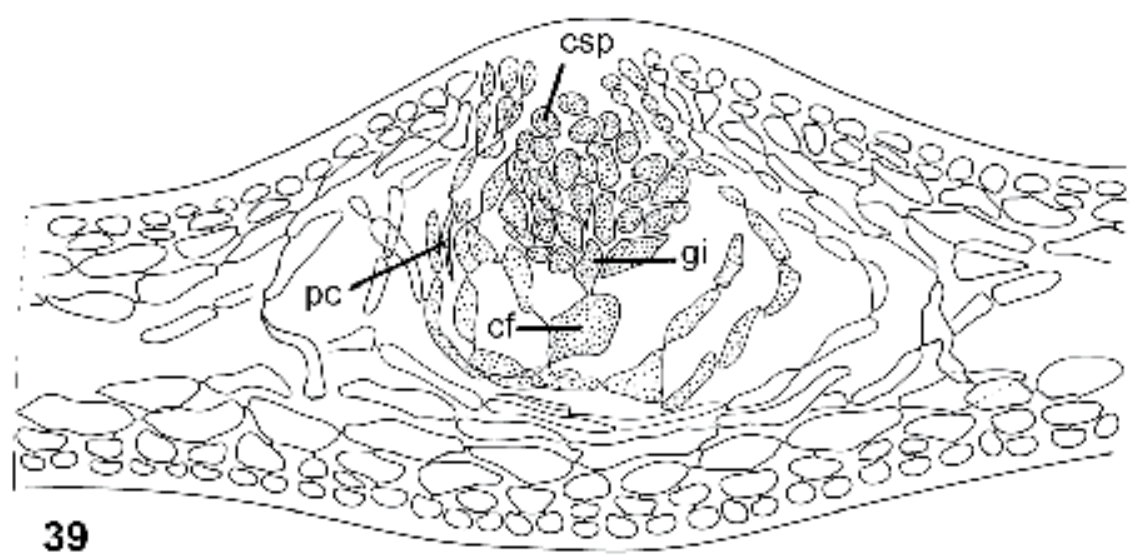

Figuras 35 - 40. Cryptonemia limensis (Kützing) Lewis. (35) Sección transversal del talo del holotipo de Cryptonemia peruviana Acleto, células corticales, filamentos medulares y filamentos con contenido denso y refringente (fr) Acleto 1339. (36) Ampolla de la rama carpogonial, con carpogonio (carp) Acleto 1339. (37) Ampolla de la célula auxiliar (caux), filamentos auxiliares (fa). Acleto 1339. (38) Sección transversal del talo cistocárpico mostrando la forma y posición de la ampolla de la célula auxiliar (caux), filamentos auxiliares de la ampolla (fa). Acleto 1339. (39) Sección transversal del talo cistocárpico mostrando el cistocarpo: pericarpo (pc), célula de fusión (cf), gonimoblasto inicial (gi) y carposporas (csp). Acleto 1339. (40) Sección transversal del tetrasporofito con tetrasporas (tsp) Acleto 1339a.

con un tricogino corto. La célula hipógina lleva una rama corta de 2 células. La ampolla de la célula auxiliar (Figs. 37, 38) es de forma cónica y consta de un filamento principal de $9-13$ células y de $3-4$ filamentos secundarios de $6-8$ células. De los filamentos secundarios se origina generalmente un filamento de tercer orden, de $2-4$ células. Las células de la ampolla son ovoides, alargadas, compresas o subglobosas, las terminales más grandes, cilíndricas, maciformes o cónicas; la célula auxiliar, es la basal de un filamento secundario, originado de la segunda o tercera célula del filamento primario, es prominente, cilíndrica, de ápice redondeado y descansa en el centro de la ampolla.

No se ha observado las fases iniciales luego de la fertilización. En los estadios posteriores, se reconoce la célula auxiliar alargada y de mayor tamaño, en comunicación con las células de la ampolla. El gonimoblasto maduro, está rodeado de un pericarpo bien definido, compuesto de las células alargadas de la ampolla y células medulares adyacentes transformadas con tal fin (Fig. 39).

No se ha observado especímenes masculinos.

El tetrasporofito (Fig. 34) es idéntico morfológicamente al gametofito femenino, en apariencia es ligeramente liso, el tetrasporangio (Fig. 40) deriva lateralmente de la segunda célula cortical y está dividida cruciadamente, de 14,4 $\mu \mathrm{m}$ de diámetro por 21,6 $\mu \mathrm{m}$ de longitud.

Material estudiado: Perú. Dpto. y Prov. Lima: bahía de Ancón, 24, octubre 1964, C. Acleto 1339 (15740) planta cis- 
tocárpica (USM), Holotipo de Cryptonemia peruviana Acleto; C. Acleto 1339a, planta tetraspórica (USM); Dpto. Lima Prov. Callao; La Punta, 5 octubre 1984, S. Chávez S.M. planta tetraspórica (USM)

Observaciones: Esta especie ha tenido distintas denominaciones desde 1849 hasta 1990, tal como se anota en la bibliografía correspondiente. Fue descrita inicialmente como Euhymenia limensis Kützing 1849 (Fig. 35) fue transferida a Halymenia limensis Sonder ex Kützing 1866, luego a Sarcodia? limensis (Sonder) De Toni 1900 y finalmente a Sebdenia limensis (Kützing) Howe 1914 así se reconoció a esta especie desde Dawson et al. (1964) hasta el presente, la descripción de la especie hecha por Dawson et al. (1964) está basada principalmente en la de Howe (1914), con adiciones correspondientes a los ejemplares estudiados $\mathrm{e}$ ilustrados (pl. 37, fig. B, pl. 52, fig. A, pl. 53, fig. A) incluyendo además a Sebdenia heteronema Howe como sinónimo.

Los ejemplares adicionales estudiados e ilustrados por Dawson et al. (1964) no corresponden a los de Euhymenia limensis Kützing 1849, basónimo de Cryptonemia limensis (Kützing) Lewis 1990; representan más bien a una especie nueva de Cryptonemia a la que denominamos Cryptonemia anconensis Acleto et Zúniga.

En efecto, Lewis (1990) estudió el tipo de Euhymenia limensis Kützing, depositado actualmente en el National Herbarium of Victoria (MEL), reconoció como lectotipo al ejemplar que figura en la ilustración de Kützing (Tabulae Phycological vol. XVI. pl. 97), dicho ejemplar tiene las características vegetativas y reproductivas correspondientes a Cryptonemia, proponiendo una combinación nueva Cryptonemia limensis (Kützing) Lewis, 1990. Lewis también estudió los holotipos de Sebdenia (?) chinchensis Taylor, Cryptonemia guaymasensis Dawson, Cryptonemia chiangii Acleto y Cryptonemia peruviana Acleto y concluyó que todas son sinónimas de Cryptonemia limensis (Kützing) Lewis.

El presente estudio nos permite reafirmar que el único sinónimo de Cryptonemia limensis (Kützing) Lewis en nuestra flora es Cryptonemia peruviana Acleto, no así Cryptonemia chiangii Acleto, Sebdenia heteronema Howe y Sebdenia? afuerensis Taylor.
Los ejemplares de Cryptonemia limensis (Kützing) Lewis, presentes en el Herbario San Marcos (USM) bajo el nombre de Cryptonemia peruviana Acleto, comprende a plantas femeninas, tetraspóricas y estériles, la mayoría completas como el holotipo $ᄋ$ Acleto 1339 (15740); las figs: 1 - 2 de Lewis (1990) más semejan porciones de los ejemplares completos de nuestra colección.

Cryptonemia chiangii Acleto, Sebdenia heteronema Howe y Sebdenia (?) afuerensis Taylor, muestran caracteres de hábitos morfológicos y reproductivos distintos y en consecuencia corresponden a otras especies de Cryptonemia que se describen en este trabajo como Cryptonemia chinchensis (Taylor) Acleto et Zúníiga, comb. nov. y Cryptonemia heteronema (Howe) Acleto et Zúniga, comb. nov. incluyéndose como sinónimo a Sebdenia (?) afuerensis Taylor. Las características diferenciales se dan con amplitud en las descripciones correspondientes.

\section{PhYLUM RHODOPHYTA \\ Clase Florideophyceae \\ ORden SEBdeniales \\ FAMILIA SEBDENIACEAE \\ Sebdenia (J. Agardh) Berthold}

\section{Sebdenia flabellata (J. Agardh) Parkinson}

Basónimo: Isymenia flabellata J. Agardh, 1899: 62, 66; Sebdenia flabellata (J. Agardh) Parkinson, 1980: 12 Millar, 1990: 328. Schneider \& Wynne, 1991, 471 - 474 Huisman, 1993: 16. Silva, Basson \& Moe. 1996: 324. Bula. Meyer and Norris 2001:354, fig. 3.; Halymenia agardhii De Toni, 1905: 1542. W.R. Taylor, 1960: 417 (proparte), pl. 51, fig.1.

Halymenia polydactyla Borgensen, 1932b: 122-124, fig. 10, pl. 4 Schneider and Searles, 1975:84. Sebdenia polydactyla (Borgensen) Balakrishnan, 1961a: 89 - 90, Balakrishnan, 1961c: 202 - 212, pl. 6, figs. 1-2, 28- 41. J.N. Norris and Bucher, 1976: 14, figs. 11 a-c, 12 a-c. Acleto, 1980: 11 - 12, figs. 14, 25 - 29. M.E. Guevara, 1989: 21 - 22, fig.9.

Figs. $41-48$

Planta de color rojo vinoso a rosado intenso, cilíndrico rígido en ejemplares pequeños, a comprimido, de textura suave, elástica en los ejemplares grandes, alcanza hasta $27 \mathrm{~cm}$ de altura, con un estípite corto hasta $5 \mathrm{~mm}$ rígido y cuneado y luego con ramificaciones dicótomas de varios órdenes, en un plano,
41

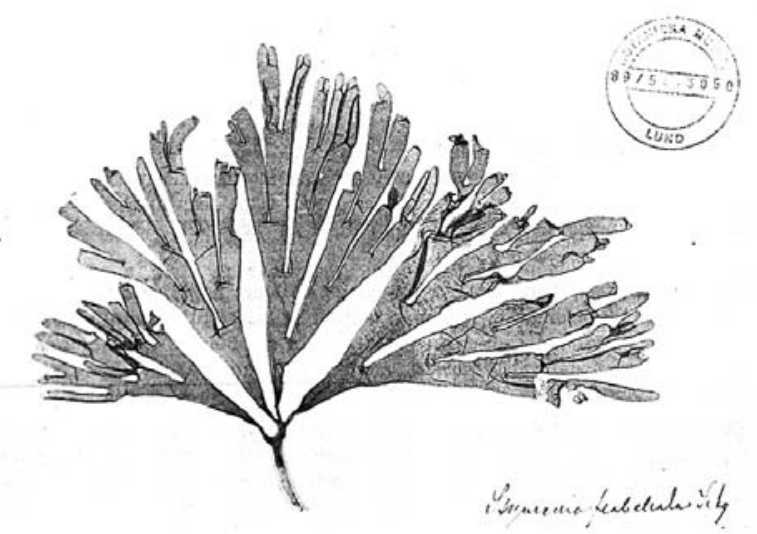

Fig. 1. Lectotype specimen of Isymenia flabellata J. Agardh [i.e, Sebdenia flabellata (J. Agardh) Parkinson], LD 22292.

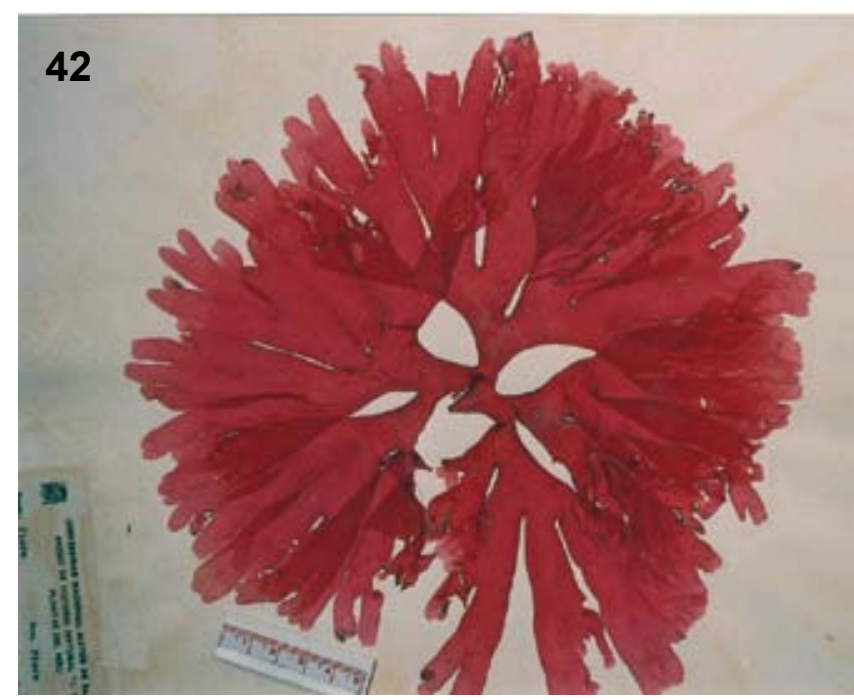

Figuras 41 - 42. Sebdenia flabellata (J. Agardh) Parkinson. (41) Lectotipo de Isymenia flabellata J. Agardh (según Scheider \& Wynne 1991). (42) Sebdenia flabellata (J. Agardh) Parkinson morfología de un ejemplar cistocárpico, Acleto 1895. 


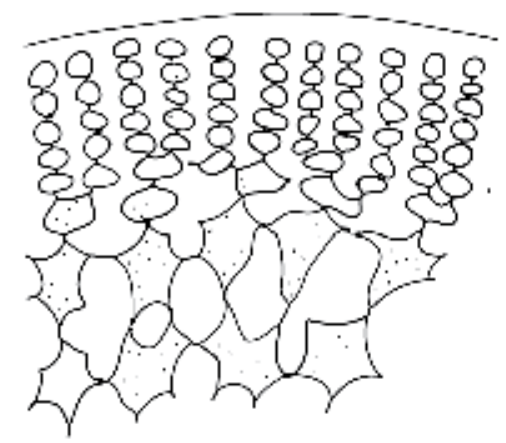

43
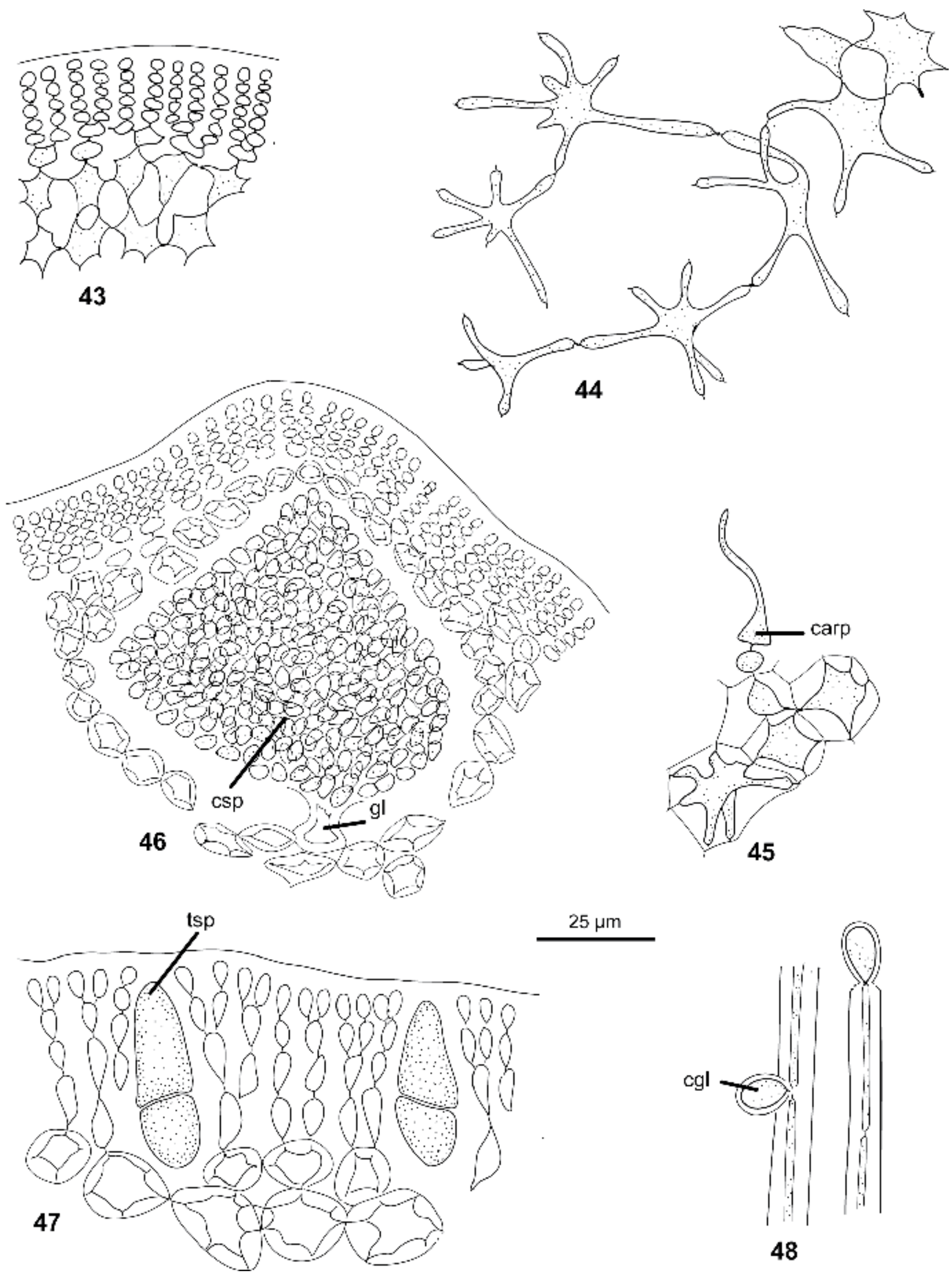

$25 \mu \mathrm{m}$

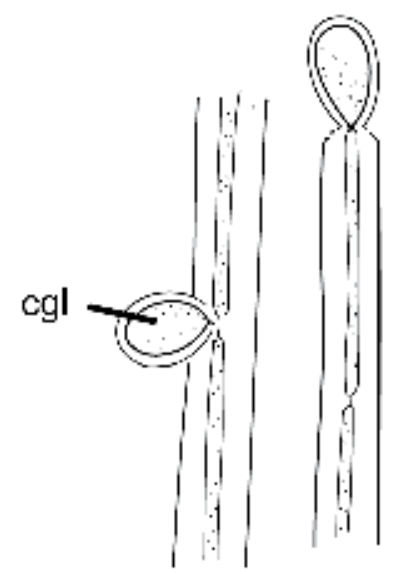

48

Figuras 43 - 48. Sebdenia flabellata (J. Agardh) Parkinson. (43) Sección transversal del talo mostrando las hileras de células corticales y células subcorticales, Acleto 1579. (44) Células ganglioideas de la zona subcortical hacia la medular mostrando prolongaciones hialinas largas, Acleto 1579. (45) Rama capogonial y carpogonio (carp) originado a partir de las células subcorticales, Acleto 1657. (46) Sección transversal del ejemplar cistocárpico, masa de carposporas (csp) originadas del gonimoblasto inicial (gi), Acleto 1657. (47) Sección transversal del talo de un ejemplar tetraspórico, con dos tetrasporangios (tsp) en la zona cortical, Acosta 537. (48) Porción de dos filamentos medulares con células glandulares (cgl), lateral y terminal respectivamente, Acleto 1579. 
en conjunto flabelado, de $1 \mathrm{a} 4 \mathrm{~cm}$ de diámetro, con el ápice ampliamente redondeado, o acuminado con el extremo romo, a veces con proliferaciones subuladas pequeñas y numerosas (Fig. 42). En sección transversal presenta una zona cortical de 4 a 6 hileras anticlinales de células pigmentadas, redondeadas de 4 a $8 \mu \mathrm{m}$ de diámetro, la subcorteza con células globosas, más grandes hacia la médula, radiadas o ganglioideas, de 15 a $24 \mu \mathrm{m}$ de diámetro, más dispersas hacia el centro y con los radios más largos, angostados próximos a las células y de mayor diámetro en las uniones con los filamentos de las células adyacentes la médula con mayor cantidad de filamentos, de diámetro uniforme $3-4,5 \mu \mathrm{m}$, dispersos irregularmente, lleva células glandulares pequeñas a diferentes niveles (Figs. 43, 44, 48).

Las plantas femeninas tienen los cistocarpos dispersos entre la zona cortical y parte externa de la zona medular de la parte media de las ramas de diferentes órdenes, con poco tejido en el pericarpo, se eleva ligeramente en la superficie del talo, con un ostiolo diferenciado y constituido por filamentos de orientación definida la masa de gonimoblasto y carposporas de forma cónica, con un pie notorio, bien diferenciado y en conjunto semeja un árbol diminuto (Fig. 46).

El tetrasporofito, con tetrasporangios de división cruciada, se ubica en la zona cortical de la parte media y tercio superior de los ejes principales y secundarios, miden de $8-10 \mu \mathrm{m}$ de diámetro por $20-25 \mu \mathrm{m}$ de longitud (Fig. 47).

Los ejemplares estudiados no incluyen a las plantas masculinas.

El registro de esta especie en la zona norte del litoral peruano, constituye una ampliación de su distribución en el Pacifico de Sudamérica. Todos los ejemplares registrados han sido colectados como material varado, posiblemente habitan en el sublitoral.

Material estudiado: Perú, Dpto. Piura, Prov. Paita, Paita, 5 enero 1970, Acleto 1579 (USM), 27 julio 1970, Acleto1657 (USM), Prov. Sechura, Parachique, 12 setiembre 1972, Acleto1895 (USM) Bayovar, Acosta 381. 537.

Observaciones: Hasta el presente Sebdenia flabellata (J. Agardh) Parkinson (Fig. 41), es la única especie de Sebdenia presente en la flora marina del Perú, fue registrada como Sebdenia polydactyla (Borgesen) Balakrishnan por Acleto (1980).

\section{Agradecimientos}

Al término de esta contribución, queremos expresar nuestro agradecimiento a los curadores de los herbarios donde están depositados los tipos de las especies estudiadas, quienes tuvieron la gentileza de atender nuestra solicitud de préstamo: Dr. Michael J. Wynne, del Herbario An Arbor, Michigan (MICH), (1987); Dra. Barbara M. Thiers, del Cryptogamic Herbarium del New York Botanical Garden (NY), (1988, 1990); Dr. W. F. Prud, home van Reinem del rijsherbarium, Leiden (L), (1989, 1990). Del mismo modo, agradecemos al Dr. Paul C. Silva del University Herbarium Berkeley, California por su gentileza en atender a nuestras consultas referentes al tema. A la Dra. Magda Chanco del Herbario San Marcos (USM) por la lectura del manuscrito y al Dr. Guillermo Pino por la traducción al latín de la descripción de la nueva especie. A Israel Acleto Z., Angélica Denegri y Frank Aliaga Livia por ayudarnos en el ordenamiento del texto de este trabajo. Y al revisor anónimo por sus comentarios y sugerencias.

\section{Literatura Citada}

Acleto O.C. 1973. Las algas marinas del Perú. Bol. Soc. Per. Bot. 6: 164

Acleto O.C. 1980. Notas sobre las algas marinas del Perú I. Nuevos Registros. Publ. Mus. Hist. Natur. Serie Botánica. 30: 1-33

Agardh J.G. 1851. Species genera et ordines algarum, vol. 2 (2:1). C. W. K. Gleerups, Lund.

Balakrishnan M.S. 1961. Studies on Indian Cryptonemiales. III Halymenia C. Ag. J. Madras Univ. Sect B. 31: 183-127

Borgesen F. 1932. Some Indian Rhodophyceae Bull. Misc. Inform: 113-134. Botanica Marina. 44: 351-360

Bula-Meyer J. \& J.N. Norris. 2001. Notes on New Records of Red Algae from the Colombian Caribbean. Botanica Marina. 44:351-360

Chiang Y.-M. 1970. Morphological studies of red algae of the family Cryptonemiaceae. University of California Publications in Botany 58: 1-83, pls. 1-10.

Codomier L. 1972. Sur la reproducion sexuée du Sebdenia rodrigueziana (J. Feldm.) comb. nov (Gigartinales, sebdeniacées) Compt. Rend. Hebd. Séances Acad. Sci., ser. D. 274: 2299-2301

De Toni G.B. 1900. Sylloge algarum. Vol. 4. Florideae. Pt. 2, pp. 287-776. Padua

Dawson E.Y. 1954. Marine red algae of Pacific Mexico. Part 2. Cryptonemiales. Allan Hancock Pacific Exped. 17 (2): 240-398

Dawson E.Y., C. Acleto \& N. Foldvik. 1964. The Seaweeds of Perú. Nova Hedwigia 13: 1-111

Gavio B., E. Hickerson \& S. Fredericq. 2005. Platoma chrysymenioides sp. nov. (Schizymeniaceae), and Sebdenia integra sp. nov. (Sebdeniaceae), two red algal species from the northwestern Gulf of Mexico, with a phylogenetic assessment of the Cryptonemiales complex (Rhodophyta). Gulf of Mexico Science 2005 (1): 38-57.

Howe M.A. 1914. The marine algae of Peru. Memoirs of the Torrey Botanical Club 15: 1-185, 44 figs, 66 plates.

Huisman J.M. 1993. Supplement to the catalogue of marine plants recorded from Rottnest Island. In Wells, F. E., Walker, D. L., D. I. Kirkman, H. \& Lethbridge, R. (Eds). The marine flora and fauna of Rottnest. Island, Western Australia. Proc. Fifth Int. Mar. Biol. Workshop, pp. 11-18 (W. Aust. Museum: Perth.)

Guevara M.E. 1989. Estudio de la morfología y estructuras reproductivas de Sebdenia limensis (Sonder) Howe, 1914. (Rhodophyta, Gigartinales). Tesis Bachiller. Facultad de Ciencias Biológicas, Universidad Ricardo Palma. 45 pp.

Kützing F.T. 1849. Species algarum. Lipsiae [Leipzig]: F.A. Brockhaus. pp. [i]-vi, [1]-922.

Kützing F.T. 1866. Tabulae phycologicae; oder, Abbildungen der Tange. Vol. 16. Nordhausen: Gedruckt auf kosten des Verfassers (in commission bei W. Köhne). pp. i-iii, 1-35, 100 pls.

Lewis J.A. 1990. Cryptonemia limensis (Kützing) Lewis, comb. nov. (Halymeniaceae, Rhodophyta) from Peru. Taxon 39: $98-104$

Millar A.J.K. 1990. Marine red algae of the Coffs Harbor region, northern New South Wales. Austral. Syst. Bot. 3: 293-593

Norris J. N. \& K. E. Bucher. 1976. New records of marine algae of the 1974 R/W Dolphin Cruise to Gulf of California. Smithsonian Contr. Bot. 34: IV + 1-122

Parkinson P.G. 1980. Halymenia, being a critical account of the confused nomenclature of Halymenia C.A. Agardh 1817 (Halymeniaceae, Cryptonemiales, Rhodophyta) with reflections on the International Code of Botanical Nomenclature and corrections to certain recent work in which it has been disregarded. pp. 1-20. Auckland: Pettifogging Press. 
Ramirez M.E. 1982. Nuevos registros de algas marinas para Antofagasta (norte de Chile) Bol. Mus. Nac. Hist. Nat., 39: 11-26

Santelices B., M.E. Ramírez \& I.A. Abbott. 1989. A new species and new records of marine algae from Chile. Brit. Phycol. J. 24: 73-82

Silva P.C., E.G. Méñez \& R.L. Moe. 1987. Catalog of the benthic marine algae of the Philippines. Smithson. Contrib. Mar. Sc. 27: 1-179

Silca P.C., P.W. Basson \& L. Moe. 1996. Catalogue of the Benthic Marine Algae of The Indian Ocean. University of California Publication in Botany. Volume 79: XIV - 1259
Taylor W.R. 1947. Algae collected by the "Hassler", "Albatross", and Schmitt expeditions. III. Marine algae from Peru and Chile. Papers Mich. Acad. Sci. Arts and Letters 31: 57-90.

Schneider C.W. \& M.J. Wynne. 1991. Lectotypification of Sebdenia flabellata (J. Agardh) Parkinson (Gigartinales, Rhodophyta). Taxon 40: 471-474.

Withall R.D. \& G.W. Saunders. 2006. Combining small and large subunit ribosomal DNA genes to resolve relationships among orders of the Rhodymeniophycidae (Rhodophyta): recognition of the Acrosymphytales ord. nov. and Sebdeniales ord. nov. European Journal of Phycology 41: 379-394. 